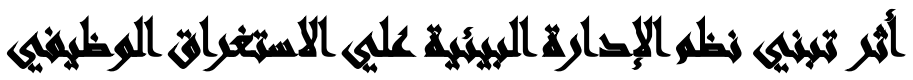

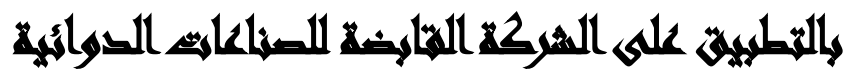

[11]

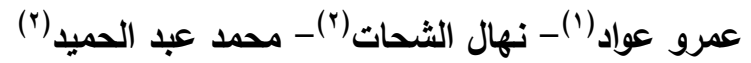

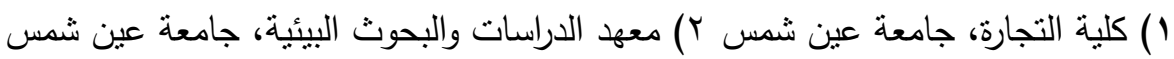

\section{المسرخليس}

يستهدف هذا البحث قياس أثز تبني نظم الإدارة البيئية علي الاستغراق الوظيفي بالتطبيق

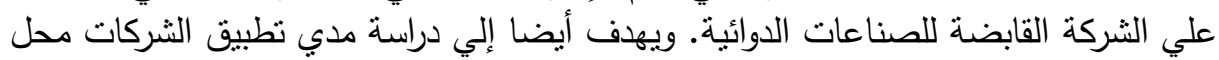

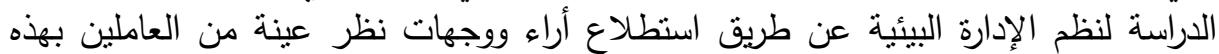

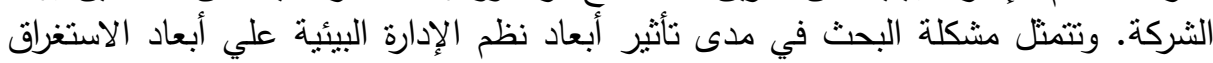

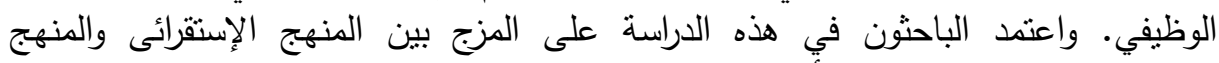

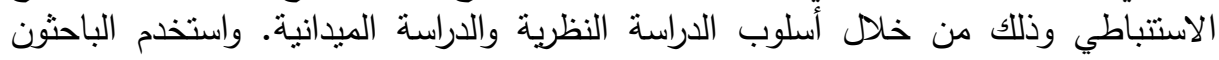

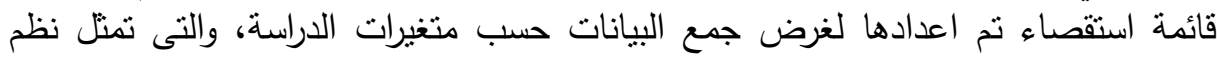

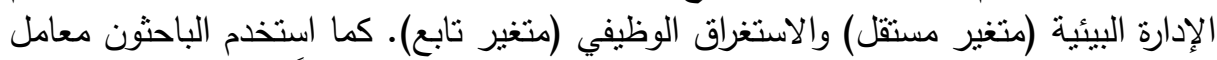

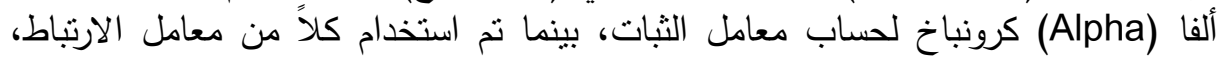

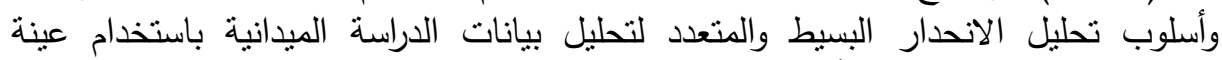

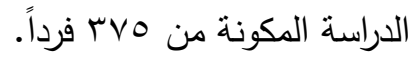

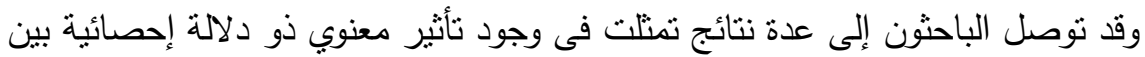

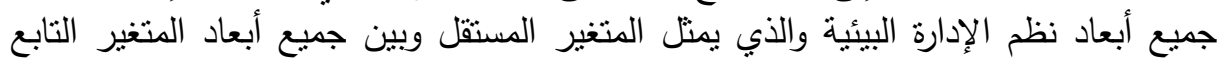

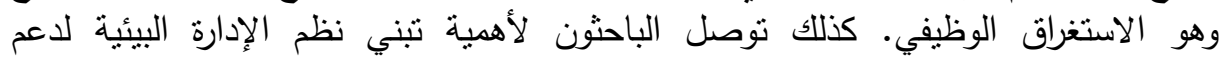
الاستغراق الوظيفي بالثركة القابضة للصناعات الإن الدوائية.

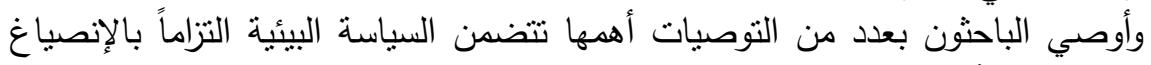

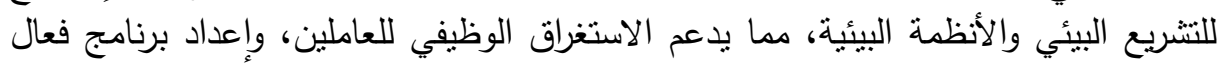

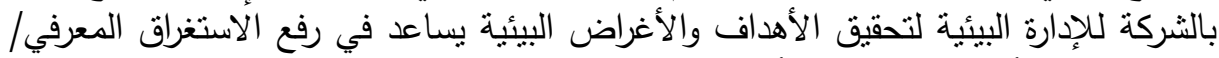

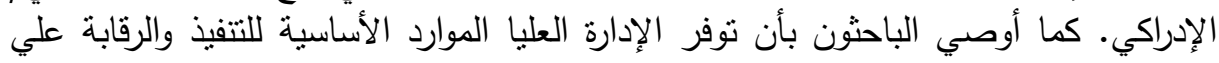

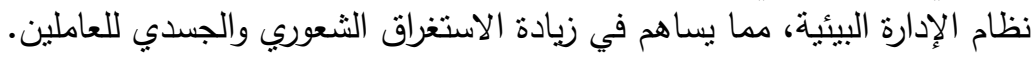


مجلة العلوم البيئية

معهد الدراسات والبحوث البيئية - جامعة عين شمس ليه

\section{8aratl}

شهدت السنوات الأخيره اهنماماً ملحوظاً بالقضايا البيئية بصفة عامة، حيث تعتبر قضية

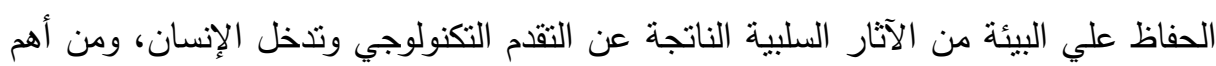
القضايا التي تحظي باهتمام العديد من الجهات سواء علي المستوى الدولي أو المحلي.

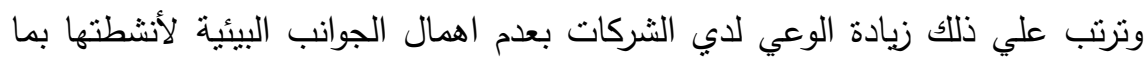

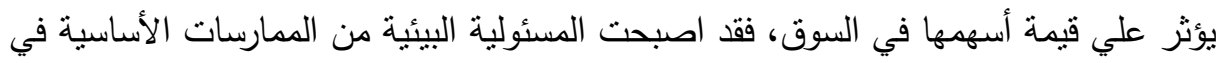

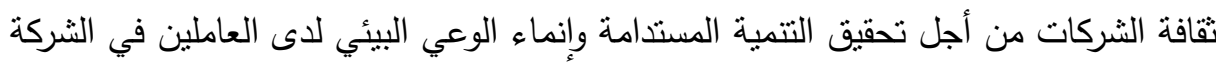

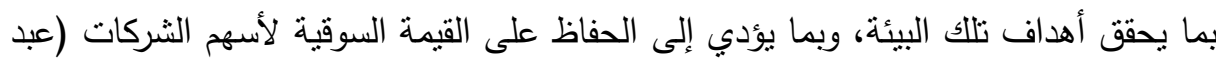

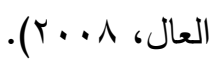
وفي هذا السياق أكدت العديد من الدراسات على ضرورة إرساء إطار متكامل لمفهوم الحوكمة البيئية (Environmental Governance) والذي يشير إلى مجموعة الأنظمة والقواعد التي تقوم بإرساء الضوابط اللازمة للحفاظ على مكونات البيئة والتتمية المستدامة،

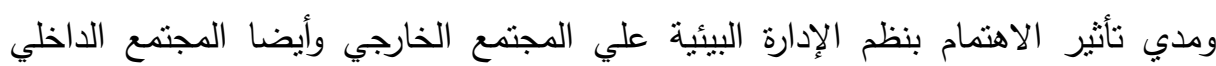
اللشركة (العاملين) وما إذا كانت هذه الممارسات الإدارية تحقق الرضا والأدارة لأندماج الوظيفي

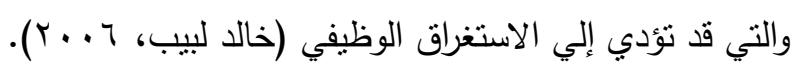

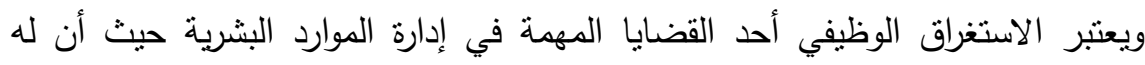

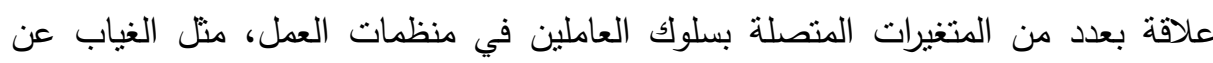

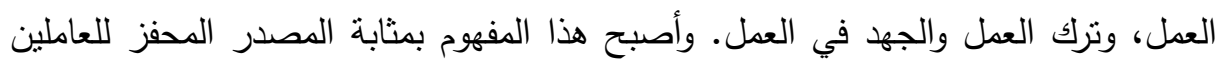
ومفتاح للتطوير الثخصي والرضا عن بيئة العمل وتوجيه السلوك نحو تحقيق الهدف .(Ekmekci, 2011)

وقد ظهرت الحاجة إلي إيجاد مصطلح لوصف شعور ارتباط الموظفين العاطفي

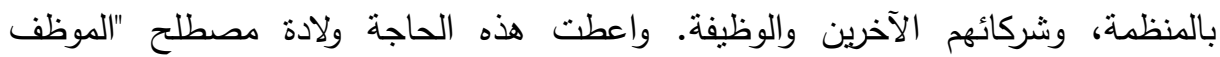
المستغرق"، ويكون الموظفون الذين يهتمون بمستقبل الثركة مستعدين لاستثمار جهودهم بالكامل لصالح المنظمة (Sodhi، 2011). 
حدد (العبادي والجاف، r r ب) أن من الضروري بالنسبة للمنظمات إيجاد طريقة

للاستفادة من جميع الموارد البشرية المتاحة لغرض الاكتفاء والنمو المتزايد، وقد ظهرت الحاجة إلى مصطلح لوصف شعور ارتباط الموظفين العاطفي بالمنظمة وشركائهم الآخرين.

\section{And I2an}

قام الباحث بدراسة استطلاعية ميدانية لتحديد مشكلة الدراسة باستخدام قائمة استقصاء

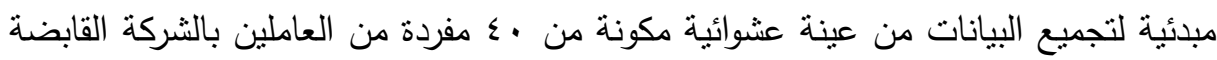

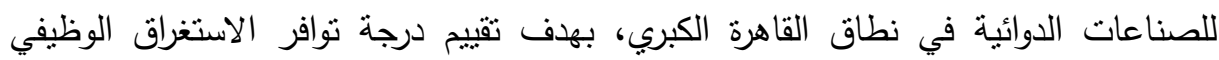
وكذلك لمعرفة مدى إدراك الإدارة لتبني نطبيق نظم الإدارة البيئية علي رضا الموظفين وإدماجهم في وظائفهم.

يمكن توضيح نتائج ما توصلت إليه الدراسة في "انخفاض مستوى الاستغراق الوظيفي لديهم وتتضح أثاره فيعدم الرغبة في تحمل المزيد من المسئوليات، فضلا عن ضعف الالتزام الوظيفي، وزيادة معدل دوران العمل" مما يؤثر ذلك علي انتاجية الثركات وتحقيق العوائد

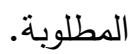

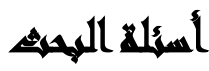

يحاول الباحثون من خلال هذه الدراسة الإجابةعلى التساؤل الرئيسي التالي: "ما أثر تبني

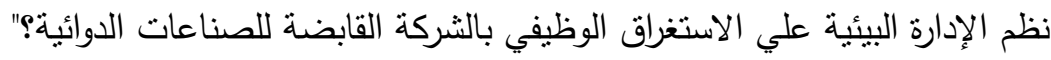
وينبثق من هذا التساؤل الرئيسي التساؤلات الفرعية التالية: 1 - ما مدي وجود نأثثر لنطبيق نظم الإدارة البيئية على الاستغراق الوظيفي بالثركات لنات محل

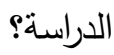

r - ب ما نوع هذا التأثنير؟

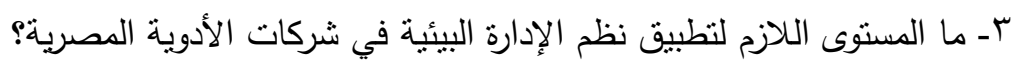

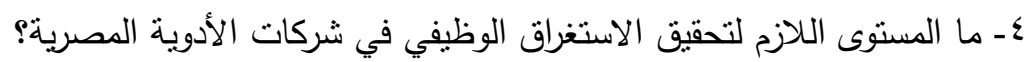




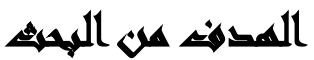

يهدف هذا البحث بشكل عام إلى دراسة واقع تبني الثركة محل الدراسة لنظم الإدارة البيئية وأثر ذلك علي الاستغراق الوظيفي للعاملين، كما نذكر من أهدافه:

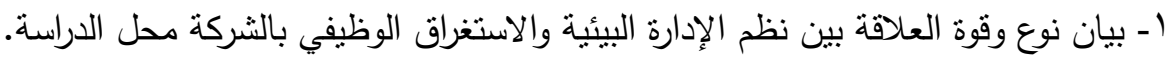

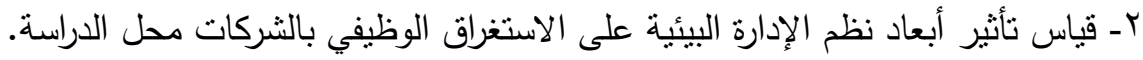
r- دراسة مدى إدراك إدارات هذه المنظمات في الوفاء بمسئوليتها تجاه المجتمع والبيئة. ع- التعرف على مستوى الاستغراق الوظيفي للعاملين بالثركة محل الدراسة.

\section{هروضر المهيه}

لتحقيق أهداف الدراسة والإجابة عن تساؤلاتها، فقد نم بناء الفروض التالية: الفرض الرئيسي الأول: لا يوجد تأثيراً جوهرياً للسياسة البيئية كأحد أبعاد نظم الإدارة

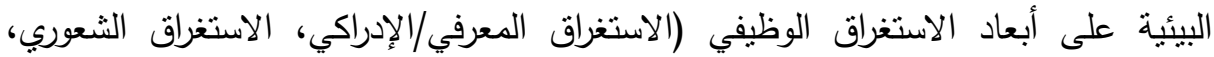
الاستغراق الجسدي) فى الثركة محل الدراسة. الفرض الرئيسي الثاني: لا يوجد نأثيراً جوهرياً للنخطيط كأحد أبعاد نظم الإدارة البيئية على أبعاد الاستغراق الوظيفي (الاستغراق المعرفي/الإدراكي، الاستغراق الثعوري، الاستغراق الجسدي) فى الثركة محل الدراسة. الفرض الرئيسي الثالث: لا يوجد نأثيراً جوهرياً للتفيذ والتتغيل كأحد أبعاد نظم الإدارة

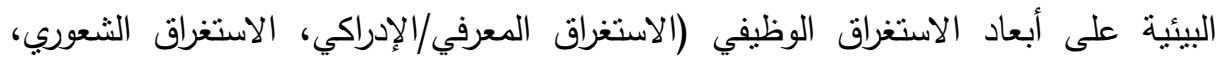
الاستغراق الجسدي) فى الثركة محل الدراسة. الفرض الرئيسي الرابع: لا يوجد تأثيراً جوهرياً للفحص والإجراءات التصحيحية كأحد أبعاد نظم الإدارة البيئية على أبعاد الاستغراق الوظيفي (الاستغراق المعرفي/الإدراكي، الاستغراق الشعوري، الاستغراق الجسدي) فى الشركة محل الدراسة. 
الفرض الرئيسي الخامس: لا يوجد نأثثراً جوهرياً للمراجعة الإدارية كأحد أبعاد نظم الإدارة

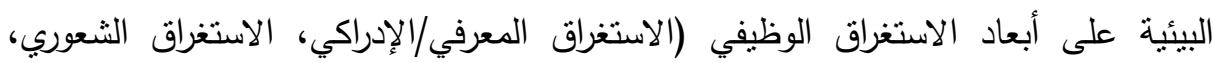
الاستغراق الجسدي) فى الثركة محل الدراسة.

\section{أهمية المهمهي}

تتبع أهمية البحث من الدور الذي تلعبه نظم الإدارة البيئية فى مواجهة ما يشهده العالم في تغيرات بيئية بسبب التطور التكنولوجي في المجال الصناعي، مما استدعي أبراز أثز

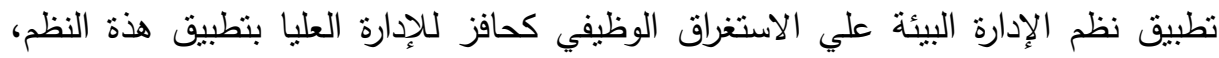

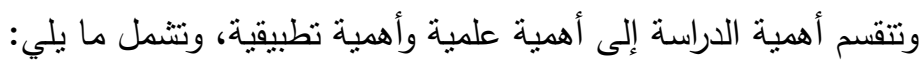

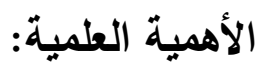

- ندرة الأبحاث والدراسات العربية والأجنبية التي تتاولت العلاقة بين نظم الإدارة البيئية والاستغراق الوظيفي (وذللك على حد علم الباحثين). وبالتالي محاولة المساهمة فى علاج الفجوة البحثية المتعلقة بنظم الإدارة البيئية وعلاقتها بالاستغراق الوظيفي. - التعرف على أثر تنبي نظم الإدارة البيئية علي الاستغراق الوظيفي.

الأهمية التطبيقية:

- إيضاح دور نظم الإدارة البيئية في شركات الدواء المصرية وأثرها علي مستوي الاستغراق الوظيفي في القطاع محل الدراسة.

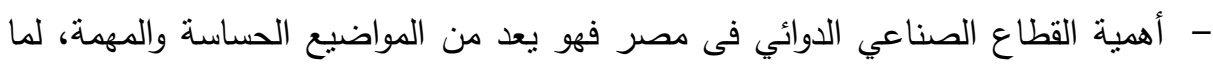

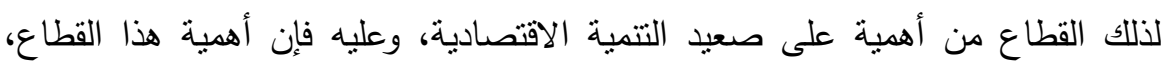
يدعو إلى إجراء منل هذا النوع من الدراسات لضمان استمراريته وتطويره.

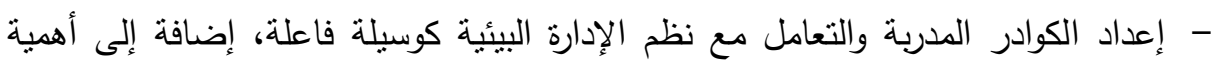

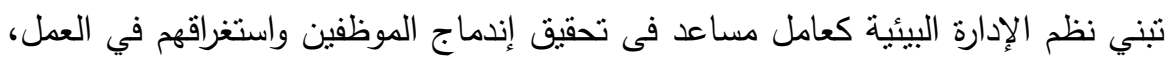
مما بساعد تللك المؤسسات في تحقيق أهدافها الاستراتيجية. 


\section{همطلحاهي الهيهي}

نظم الإدارة البيئية: ذلك الجزء من المنظومة الإدارية الكلية، والذي يتضمن الهيكل التتظيمي والأنشطة التخطيطية والمسئوليات والعمليات لتتفيذ وصبانة وتطوير السياسة البيئية

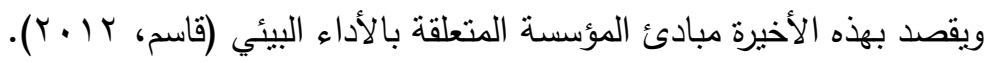
الاستغراق الوظيفي: هي الدرجة التي يتطابق فيها الفرد سيكولوجيا مع عملة وبالتالي ينظر

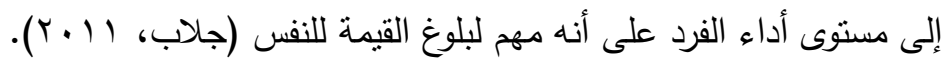

\section{السراسايت الهايري}

الاراسات المتعلقة بنظم الإدارة البيئية: دراسة (Brattesta, 2011): هدفت هذه الدراسة إلي تقديم أربع نماذج أدخل عليها التعاون

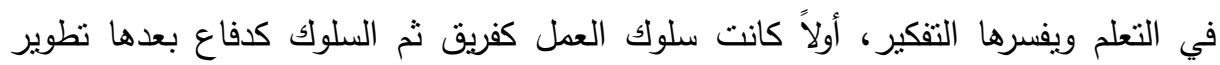

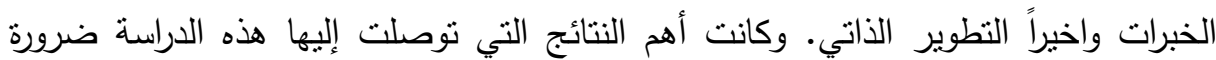

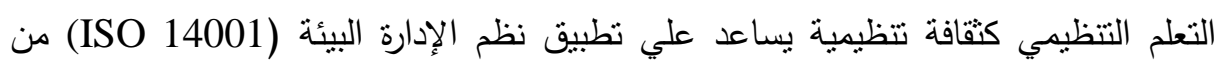
خلال قيام الثركة بتعلم رفع النفايات عن طريق الوسائل الحديثة من أجل حماية البيئة. دراسة (محمد، Y Y • Y): هدفت هذه الدراسة إلي تحسين مستوى تطبيق المنظمة لمعايير نظم الإدارة البيئية، وتحديد العوامل التى تقف وراء تحديد مستوى تبني نظام الإدارة البيئية في المنظمة. توصل الباحث إلى أن هناك تأثثير معنوي للثقافة التنظيمية في نتبي نظام الإدارة ISO البيئية، إعطاء درجة اهتمام أكبر بتحقيق تطبيق متطلبات نظام الإدارة البيئية 14001

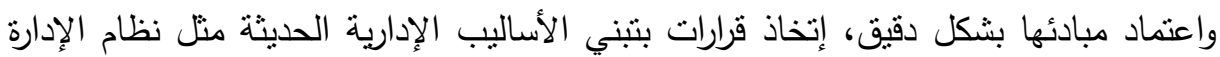
البيئية 14001 ISO لتحسين وتطوير الأداء البيئي على الددى الطويل.

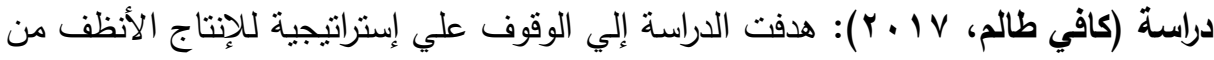

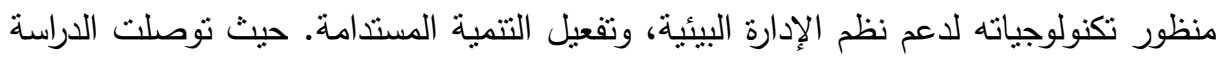

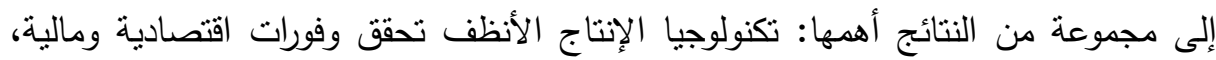


وتناعد علي الوصول إلي تحسينات بيئية للأسواق العالمية، وأن الإنتاج الأنظف هو الطريق

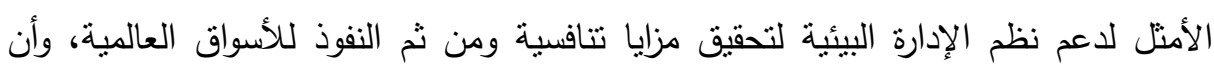
الإنتاج الأنظف طريق عملي لنطبيق التتمية المستدامة ويسمح بإنتاج أكبر وأكثر كفاءة. دراسة (حليمة، Y Y †): هدف هذه الدراسة تحديد مكامن الفاعلية لكل آلية متاحة في الإدارة البيئية، ورفع الغموض حول الفاعلية التي تحققها نظم الإدارة البيئية في ظل انتثارها العالمي الواسع، وقد توصلت الدراسة إلى عدة نتائج أهمها:

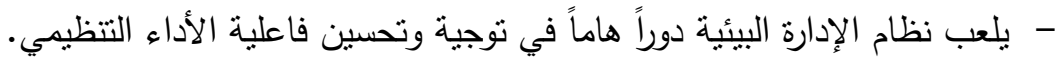
- إن الأداء التتغيلي والتحكم في حجم الآثار البيئية لا يرتبط بنظام الإدارة البيئية، أنما ليأين تلعب التكنولوجيا النظيفة الدور الأساسي في هذا المجال. - إن نظم الإدارة البيئية وفق منطلبات 14001 ISO تحقق فاعلية متعددة الأبعاد فيما يخص الأداء البيئي.

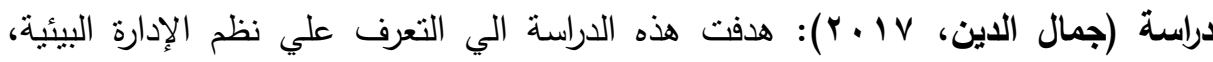

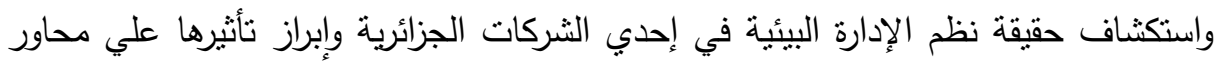
الأداء الاستراتيجي لها. وقد توصلت الدراسة إلى عدة نتائج أهمها:

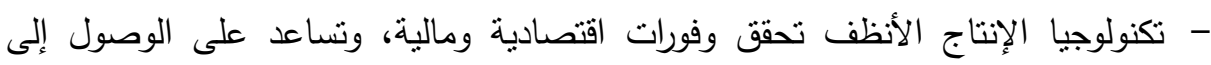
تحسينات بيئية للأسواق العالمية. - إن الإنتاج الأنظف هو الطريق الأمنل لدعم نظم الإدارة البيئية لتحقيق مزايا تتافسية ومن ثم النفوذ للأسواق العالمية. - إن الإنتاج الأنظف طريق عملي لنطبيق النتمية المستدامة ويسمح بإنتاج أكبر وأكثر كفاءة. الاراسات المتعلقة بالاستغراق الوظيفي: دراسة (Khan and Nemati, 2011): هدفت هذه الدراسة تحديد أثر عملية التكيف التنظيمي على الاستغراق الوظيفي للعاملين الجدد. كما نوصلت الدراسة إلى عدة نتائج من أهمها: 
- وجود فروق معنوية في درجات الانغماس وفقاً لاختلاف الصفات الشخصية لمركز التحكم. - وجود علاقة ارتباط موجبة بين المناخ التتظيمي الموجه بالعلاقات ودرجة الانغماس ولغاس الوظيفي. - وجود فروق معنوية في درجات الانغماس الوظيفي وفقاً لاختلاف النوع وترجع الفروق إلى الى الإناث حيث يظهرون درجات الانغماس أعلى مقارنة بالأكور . - عدم وجود فروق معنوية في درجات الانغماس الوظيفي وفقاً لاختلاف العمر والحالة الاجتماعية والمؤهل العلمي ومدة الخدمة.

دراسة (Omoniyi and Adedapo, 2012): تشير هذه الدراسة إلى العلاقة بين الاستغراق الوظيفي والالتزام التنظيمي والأداء الوظيفي. حيث توصلت الدراسة إلى أن

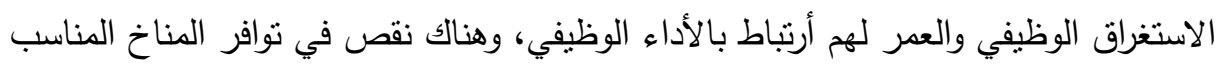

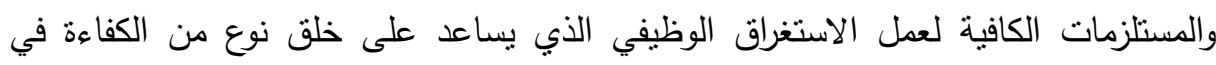
الأداء الوظيفي.

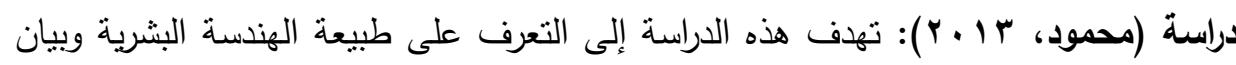

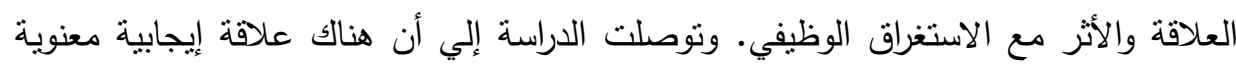

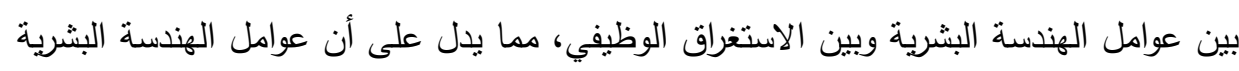
كلما نوافرت في بيئة العمل كلما ارتفع مستوى الاستغراق الوظيفي لدى الموظفين.

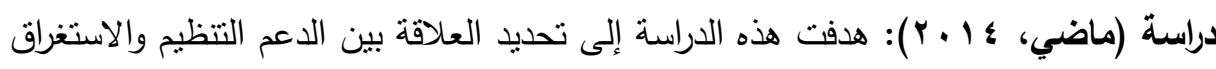

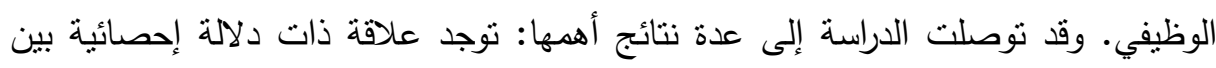

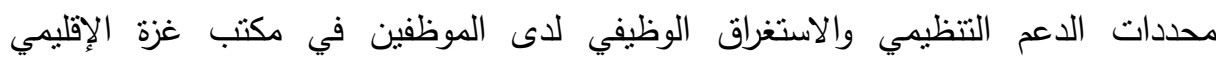
(الأونروا)، وأن مستوى الاستغراق الوظيفي مرتفع لدى العاملين في مكتب غزة الإقليمي الإني الأونروا.

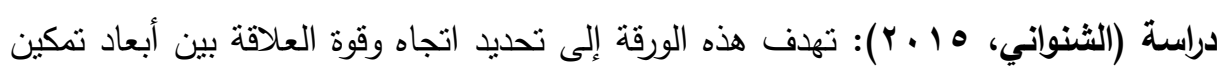

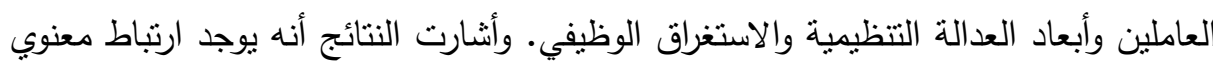

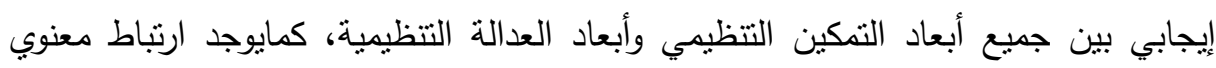


إيجابي ضعيف بين جميع أبعاد التمكين التنظيمي والاستغراق الوظيفي، وأيضاً يوجد ارتباط معنوي إيجابي ضعيف بين جميع أبعاد العدالة التتظيمية والاستغراق الوظيفي.

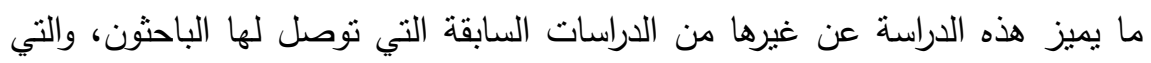
تساعد في الاثراء المعرفي للاراسة، وبالرغم من ذللك فإن كثيراً من هذه الدراسات وإن نثان نثابهت أهدافها فقد تختلف من ناحية التطبيق، في المكان والزمان، حجم العينة، ومتغيرات أخري.

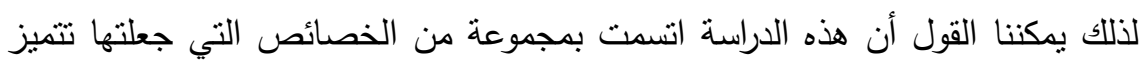

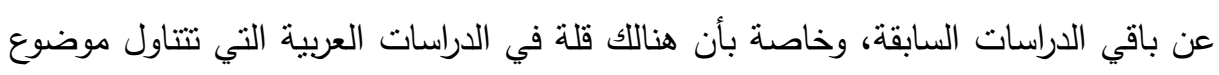

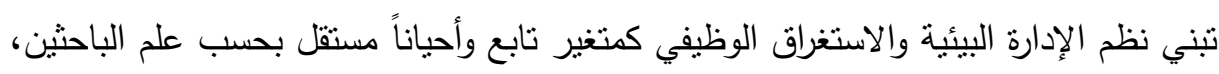

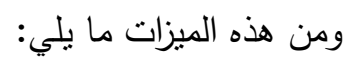
- تميزت هذه الدراسة باختيارها بالمجتمع الذي طبقت عليه، حيث تمت الدراسة علي قطاع

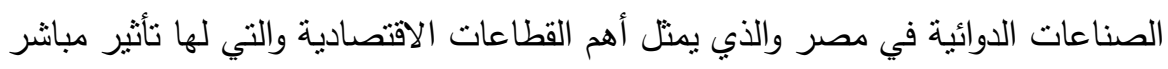

$$
\text { علي البيئة. }
$$

- تتاولت هذه الدراسات نظم الإدارة البيئية وتأثثرها على الاستغراق الوظيفي، وعلى حسب

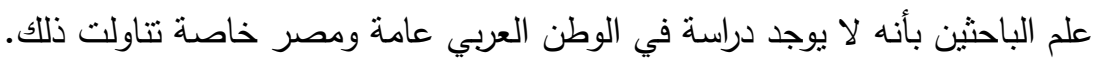
- تساهم هذه الدراسة في رفع المخزون المعرفي حول واقع تبني نظم الإدارة البيئية

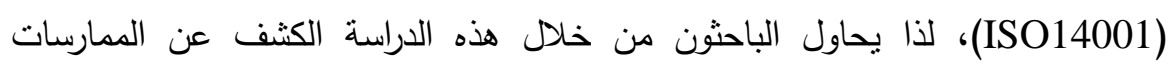
الخاصة بذلك المفهوم وأهم معوقاته وسبل نطبيقة في قطاع التطبيق من أجل بناء إطار

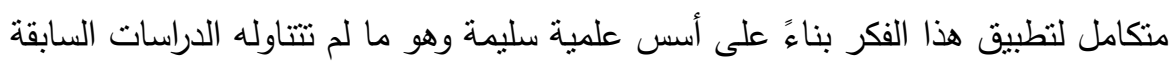
من قبل علي حد ما وصل اليه الباحثون من دراسات.

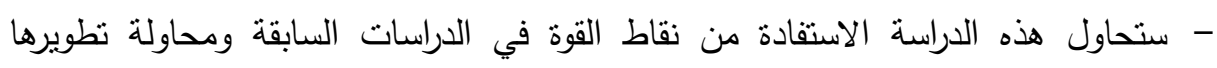

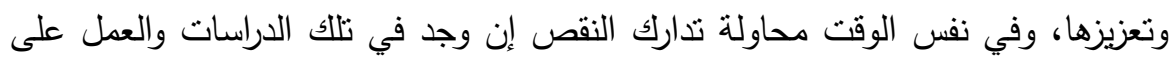
إغنائها قدر المسنطاع. 
مجلة العلوم البيئية

معهد الدراسات والبحوث البيئية - جامعة عين شمس ليه

\section{الإطار اللزظليه}

نظم الإدارة البيئية:

ماهية نظم الإدارة البيئية: بلورت أنظمة الإدارة البيئية العديد من الأفكار مثل الإدارة الخضراء والإدارة النظيفة، وتعد متل هذه الأفكار وتعد مثل هذه الإجراءات والأفكار جزء لا يتجزء من الممارسات والعمليات اليومية، بالإضافة إلي توفير أنظمة العمل التي تسعي إلي تكامل الأهداف البيئية باتخاذ القرار (Porter \& Van. 1995). تعرف نظم الإدارة البيئية بأنها هيكل لإدارة المنظمات من أجل تقييم تأثيراتها البيئية، كونه جزءاً من نظام الإدارة في المنظمة يستخدم في نطوير وتتفيذ السياسة البيئية وإدارة الجوانب البيئية (Gallagher, 1999). كما تعرف بأنها جزء من نظام الإدارة في المنظمة بسعي إلي تطوير وتتفيذ سياستها

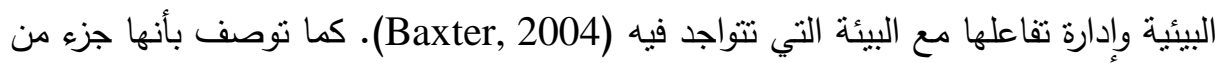
نظام الإدارة الكلي الذي يتضمن الهيكل التظيمي، وأنشطة التخطيط، والمسئوليات، والإجراءات، والعمليات، والموارد لنطوير وتتفيذ وتحقيق المراجعة والمحافظة علي السياسة البيئية (2002 : 1405 (ISO).

متطلبات تحقيق نظم الإدارة البيئية: يستعرض الباحثون فيما يلي منطلبات المواصفة القياسية

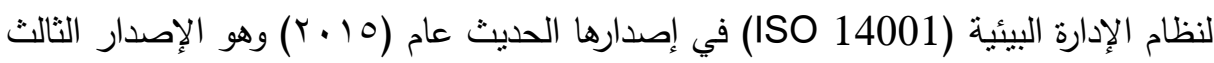

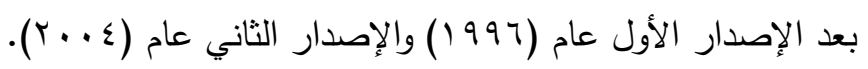

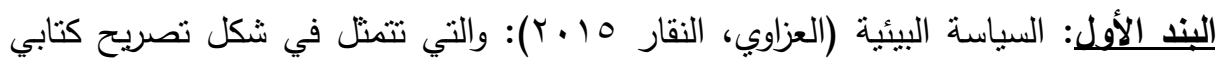

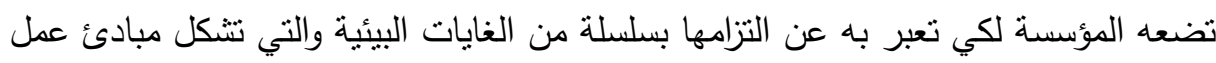

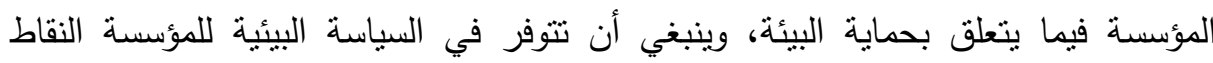

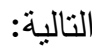
1. أن تكون مناسبة لطبيعة وحجم التأثيرات البيئية لأنشطتها وخدماتها ومنتجاتها. r. أن تتضمن الالتزام بالتحسين المستمر والحد من التلوث. 
r. أن تتضمن الالتزام بالتشريعات والقوانين البيئية والمتطلبات الأخرى التي لها علاقة

ع. أن تكون موثقة ومعلنة لكل العاملين.

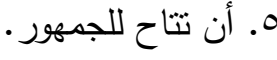

النيد الثاني: التخطبط ويضم الخطوات التالية:

ا ـ تحديد الجوانب البيئية: أي تحديد الأنشطة التي لها آثار ملموسة على البيئة، ومن أمتلة ذللك ما يلي: (انبعاث الغازات، استهلالك الطاقة، تسرب المواد السامة، النفايات، هدر

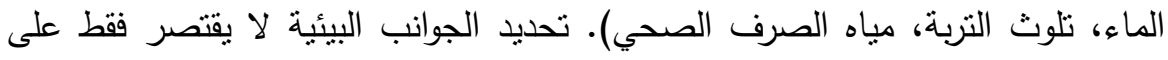

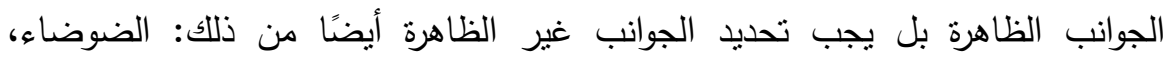

$$
\text { الروائح، الإشعاع. }
$$

r. المتطلبات القانونية وغيرها: حيث يجب على المؤسسة أن تضع نظاماً يلم بالمتطلبات

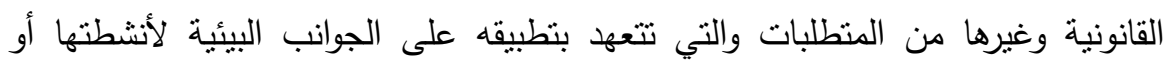
منتجاتها، ومن بين تلك المنطلبات نذكر ما يلي: أ- القوانين البيئية السارية. ب- الضوابط والتعليمات المتعلقة بالنشاط الإنتاجي.

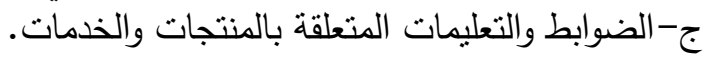

r. الغايات والأهداف: حيث يجب على المؤسسة ان تضع أهداف وغايات (أغراض) موثقة لكل وظيفة ومستوى في الهيكل التنظيمي، كما يجب أن تتناغم هذه الأهداف والغايات مع الهع السياسة البيئية للمؤسسة، ويمكن تعريف الغاية البيئية على أنها الهدف البيئي الثنامل الناشىء عن السياسة البيئية الذي تسعى المنظمة إلى تحقيقه. كما أن الغايات البيئية تكون ليهي

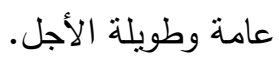

ع. برنامج الإدارة البيئية:حيث يجب لاجل، على المؤسسة أن تضع برنامج (برامج) لبلوغ الغايات والأهداف المسطرة من قبل والذي يتضمن مجموعة من الإجراءات نذكرها كما يلي:

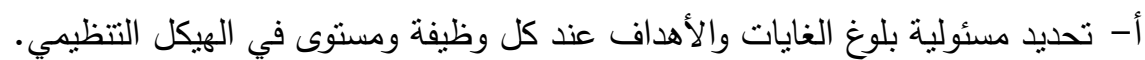

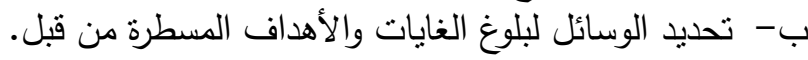

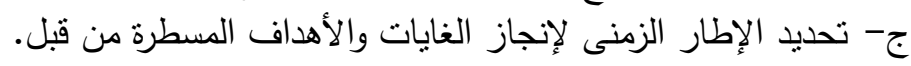

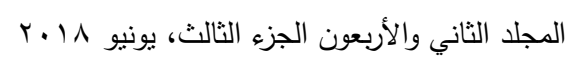


البنـ الثالث: التتفيذ والتشغيل ويضم هذا المتطلب العناصر التالية: 1. التنظيم والمسؤوليات: حيث يجب على المؤسسة القيام بما يلي:

• تحديد وتوثيق المهام والمسؤوليات لجميع الأفراد المعنيين بنظام الإدارة البيئية. • • توفير الموارد اللازمة لتنفيذ ومراقبة إجراءات الخطة البيئية. r. التدريب والتوعية: حيث يجب على المؤسسة القيام بما يلي: • تحديد احتياجاتها التدريبية، حيث تثير مواصفة الإيزو رقم 14001 إلى نوعين من التدريب، الأول متخصص بالأفراد الذين ينجم عن أعمالهم آثار بيئية مهمة، والثاني يأخذ

$$
\text { شكل التوعية البيئية. }
$$

• المحافظة على الإجراءات التي تضمن توعية العاملين بالمؤسسة بالقضايا البيئية. تشير المواصفة الدولية الإيزو 14001 إلى أن التدريب الفعال يكون من خلال تحقيق

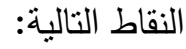

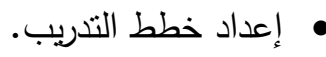
• تحديد الاحتياجات التدريبية. • التأكد أن برنامج التدريب يتماشى مع القوانين واللوائح وباقي منطلبات نظام الإدارة البيئية. r. الاتصالات: حيث يجب على المؤسسة أن نقوم بمجموعة من الإجراءات التي تتعلق بما يلي: • الاتصالات الداخلية والتي تتم بين مختلف الوظائف والمسئوليات داخل المؤسسة. • • الاتصالات الخارجية والتي تتم بين المؤسسة وأطراف خارجية. ع. توثيق نظام الإدارة البيئية: حيث يجب على المؤسسة الاحتفاظ بمجموعة من المعلومات التي تتعلق بالونائق التي تصف منطلبات نظام الإدارة البيئية سواء في شكل ورقي أو أونئي

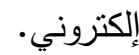
ه. التحكم في الوثائق:حيث يجب على المؤسسة أن تضع وتصون إجراءات التحكم في الوثائق بما يضمن تحقيق ما يلي: • أن تكون معلومة المكان ومحفوظة بطريقة منظمة. 


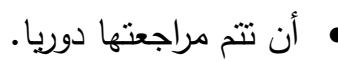

• أن تكون متاحة لجميع العمال الذين لهم صلة بنظام الإدارة البيئية.

T. التحكم فى العمليات: حيث يجب على المؤسسة تحديد وتخطيط تلك العمليات المتعلقة بالجوانب البيئية المهمة لتوافق السياسة البيئية وتحقق الغايات والأهداف البيئية، مع مراعاة

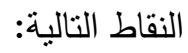

• إنثاء والمحافظة على إجراءات موتقة تغطي الحالات التي يؤدي غيابها إلى الانحراف عن

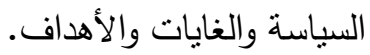

إنشاء والمحافظة على إجراءات تتعلق بالجوانب البيئية المهمة للسلع والخدمات وإيصال

$$
\text { تللك الإجراءات إلى الموردين والمتعاقدين. }
$$

V. الاستعداد والاستجابة للطوارئ: حيث يجب على المؤسسة أن تكون مستعدة للحالات الطارئة وذلك بمراعاة أن تضع وتصون إجراءات تحدد الحوادث للحالات الطارئة وكيفية الاستجابة لها، وكذلك أن تراجع وتحدث إجراءات الاستجابة للطوارئ كلما كان ذلك ممكناً

$$
\text { وخاصة بعد حدوث حالات طارئة. }
$$

البند اللرايع: الفحص والإجراءات التصحيحية ويضم هذا المتطلب العناصر التالية:

ا. الرقابة والقياس: حيث يجب على المؤسسة حسب مواصفة الإيزو رقم 14001 أن تقوم

$$
\text { بما يلي: }
$$

إنثاء والمحافظة على إجراءات موثقة لمتابعة وقياس الأنشطة التي لها تأثثر هام على بلى

$$
\text { البيئة. }
$$

• تسجيل المعلومات المتعلقة بالرقابة على الأداء وإجراءات القياس والمطابقة مع الغايات

$$
\text { والأهداف البيئية. }
$$

r. عدم المطابقة والإجراءات التصحيحية والوقائية: بعد القيام بعملية الرقابة والقياس يتم

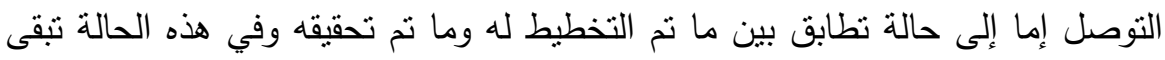
الوضعية كما هي، أما إذا تم التوصل إلى حالة عدم المطابقة فإن مواصفة الإيزو

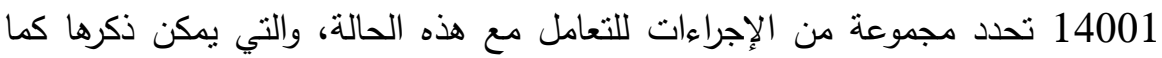

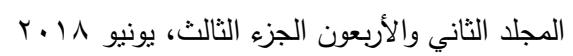




$$
\text { • تحديد أسباب حالات عدم المطابقة. }
$$

اتخاذ الإجراءات اللازمة لمعالجة أو التخفيف من التأثيرات البيئية.

r. ضبط السجاتاتحيث يجب على المؤسسة أن تضع مجموعة من السجات البيئية بما

$$
\begin{aligned}
& \text { يضمن تحقيق ما بلي: } \\
& \text { • }
\end{aligned}
$$

• أن تكون محفوظة بطريقة يسهل الوصول إلبها وكذا وقايتها من التلف أو الفقدان. ع. مراجعة أو تدقيق نظام الإدارة البيئية:تلزم مواصفة الإيزو رقم 14001 المؤسسة بضرورة إجراء عملية تحقيق يقوم بها فريق داخلي أو خارجي، تهدف إلى التقييم الموضوعي للنظام ومدى مطابقته لمتطلبات مواصفة الإيزو رقم 14001، وإبلاغ الإدارة العليا بنتائج تللك العملية من خلال التقارير المعدة لهذا الغرض.

البند الخامس: مراجعة الإدارة: على الإدارة العليا للمؤسسة أن تقوم على فترات تحددها بمراجعة نظام الإدارة البيئية، للتأكد من استمراريته وكفاءته وفاعليته، كما يجب توثيق هذه المراجعة، حتى تصل إلى هدفها المنشود وهو التحسين المستمر لنظام إدارة البيئة.

\section{الاستغراق الوظيفي:}

تعريف الاستغراق الوظيفي: هو درجة الارتباط النفسي بالعمل، بحيث يكون منهكاً فيه بجديه. والعامل الذي يكون انهماكه واندماجه عالياً في عملة يؤدي مختلف الفعاليات والأنشطة التي يتضندها عملة بجد ونشاط واندفاع إذ يرتبط بالنواحي العقلية والعاطفية معاً، ويتأثر الاستخراق الوظيفي بالعديد من المؤثرات، منها المستوى العاطفي، وبتضح ذلك من خلال الآثار الايجابية على الفرد (مجال السعادة والرضا والتقدير العالي للذات)، وعكس ذللك صحيح عندما ينخفض مستوى الاستغراق الوظيفي، فيتضح التأثير السلبي على مشاعر الفرد العاملالموظف ( القلق، والضيق والكآبة، والإحساس باليأس). كما يُعد الاستغراق الوظيفي هو أحد المفاهيم التي أضيفت مؤخراً إلى ميدان السلوك التظيمي. وفي الوقت الذي يوجد فيه اتفاق تام بين الباحثين حول معنى هذا المفهوم إلا إن الاختلاف جاء فيما قصد عمليا منه. والاستخراق الوظيفي يعبر عن الدرجة التي يتطابق فيها

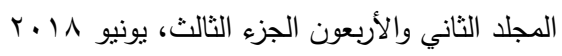


الفرد سيكولوجيا مع عملة وبالتالي ينظر إلى مستوى أداء الفرد على أنه مهم لبلوغ القيمة

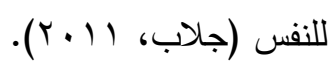

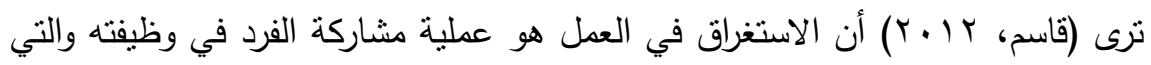
تستوعب كل طاقته من أجل تحقيق أهداف الفرد وشعوره بكونه مساهماً فعالاً ومشاركاً في إنخاذ القرارات التي تعم وظيفته.

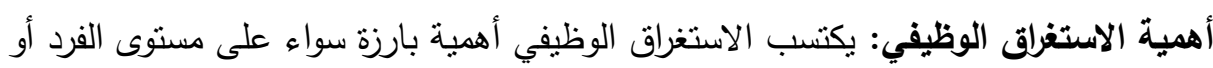

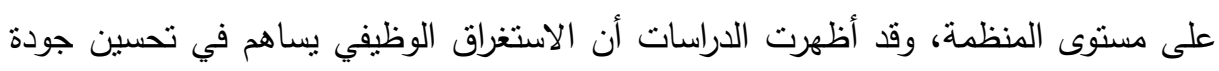
حياة العمل بالمنظمة ومن ثم تحسين معيشة العاملين وبالتالي زيادة رغبتهم في العمل والبقاء في المنظمة (Hafer \& Martin, 2006). قد ربط كل من (Lambert \& Paoline, 2012) الاستغراق الوظيفي بنتائج العمل، إذ

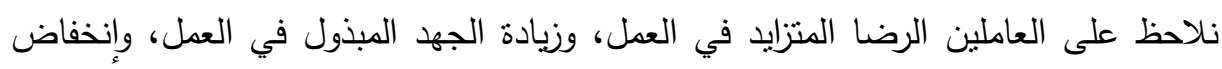

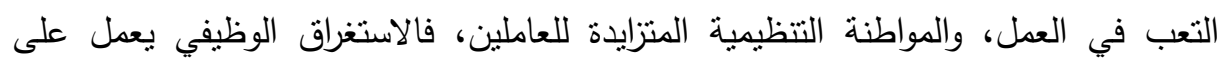

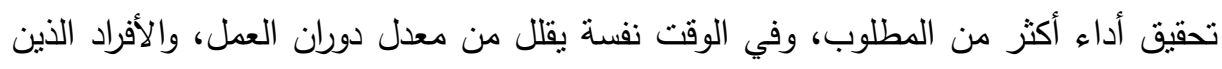

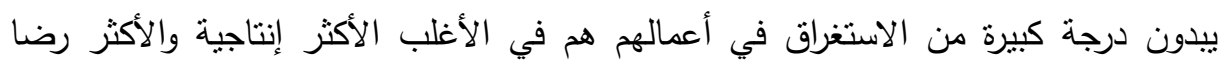

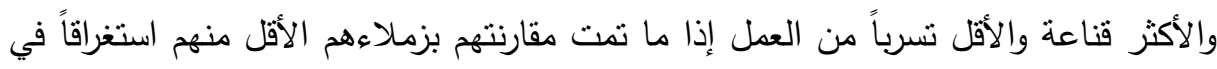

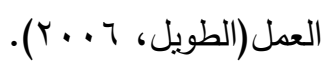

كما يساعد الاستغراق الوظيفي في خفض مستويات التسرب الوظيفي وانخفاض نسبة الغياب والحد من مشكلة التأخير عن العمل، فضلاً عن انخفاض فئريات معدل دوران العاملين، وضمان استقرار العمالة والانتظام في العمل، مما يؤثر على انخفاض تكلفة العمل (الثنواني، 


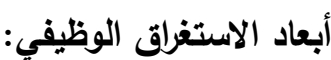

1-الاستغراق المعرفي الإدراكي: من الناحية الإدراكية، ينغس الأفراد بشكل كامل في ممارسة

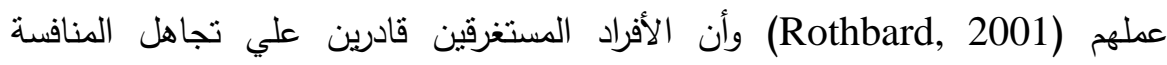
ويركزون بشكل مكثة علي المهمة التي أعطيت لهم، ومن جهة أخرى بعني مفهوم فلك الاستغراق الوظيفي "عدم وجود اهتمام نحو مهام عمل الفرد" (Rich, 2006). r- الاستغراق الثعوري: يعني الاستغراق الثعوري- العاطفي- وجود علاقة قوية بين عواطف، أفكار، ومشاعر الفرد وبين المنظمة (Kahn, 1990) مما يؤدي إلي مشاعري الإني الحماس والفخر (Rich, 2006) وعلى العكس من الاستغراق الثعوري يبرز مفهوم الغياب الثعوري (Kahn, 1990) الذي يتميز بفصل العاطفة مع الآخرين. r-الاستغراق الجسدى: من الناحية الجسدية (المادية)، يعني الاستغراق توجيه الطاقات المادية للمرء نحو استكمال مهمة معينة (Rich, 2006).

\section{إجبراءيه التصاسمة}

اعتمد الباحثن في هذه الدراسة على المزج بين المنهج الإستقرائى والمنهج الاستتباطي وذللك من خلال أسلوب الدراسة النظرية والدراسة الميدانية وذللك كما يلي:

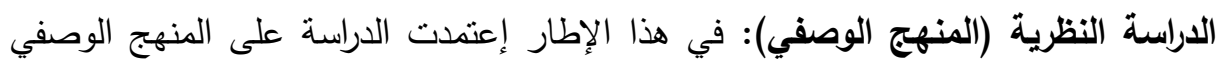

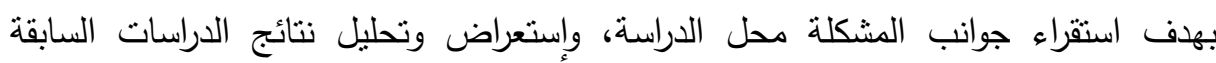

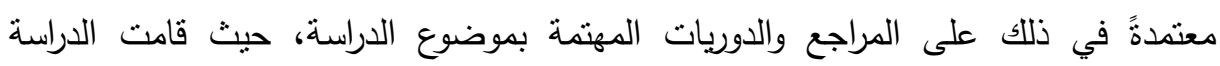

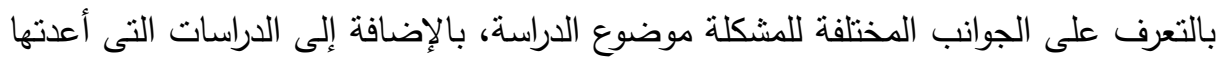

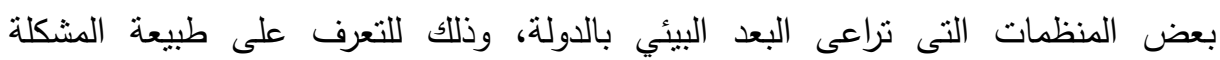

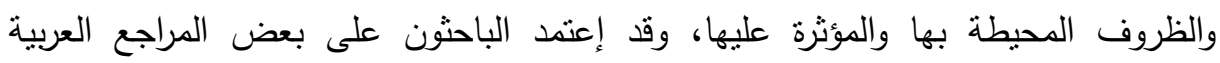

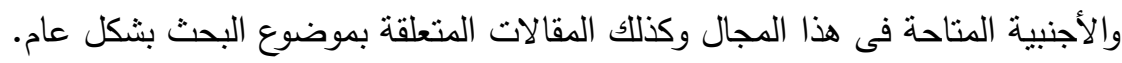
الدراسة الميدانية (المنهج التحليلي): إعتمد الباحثون في إجراء الدراسة الميدانية على قائمة

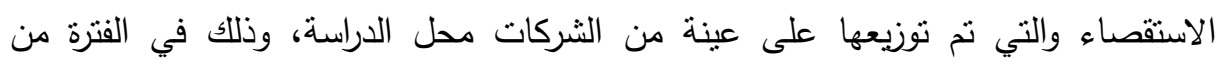

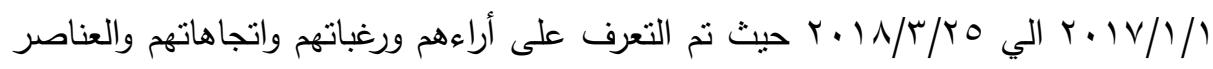


الغير مرضية التى تواجهرم وانطباعاتهم واقتراحاتهم، وقد تم استخدام الأساليب الإحصائية في

تحليل البيانات والمعطيات التي تم جمعها.

قد توصلت الدراسة إلى وجود فجوة بحثية لم تغطيها العديد من الدراسات السابقة، ومن

ثم اهتمت الدراسة بإجراء دراسة إستكثافية في المجال التطبيقي، ثم تم استعراض نتائج الدراسة الميدانية وتحليلها، ومن ثم فإن الدراسة قد تتاولت ذلك في موضوعين أساسيين هما: أسس الدراسة الميدانية، ونتائج الدراسة الميدانية ومناقتشها، حيث استخدم الباحثون الأسلوب الإحصائي الأنسب للتحليل، وهو معامل ألفا (Alpha) كرونباخ لحساب معامل الثبات، بينما استخدم كلاً من معامل الارتباط لبيرسون، وأسلوب تحليل الإنحدار البسيط والمتعدد لتحليل بيانات الدراسة الميدانية، ولما كانت البيانات قد جاءت منظمة فى شكل جداول تكرارات من خمسة أعمدة وصفين، تمثل الصفوف عينة الدراسة، وتمثل الأعمدة استجابات الأفراد على لخى أسئلة الاستقصاء والتى تم ترتيبها تتازلياً من موافق تماماً إلى لا أوافق مطلقاً. أسلوب وأدوات الدراسةة: بمكن توضيح كلاً من مجتمع وعينة الدراسة كما يلي:

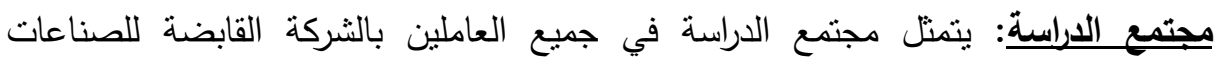
الدوائية، وقد قام الباحثون بتخصيص هذه الدراسة وتطبيقها على العاملين بشركات الصناعات

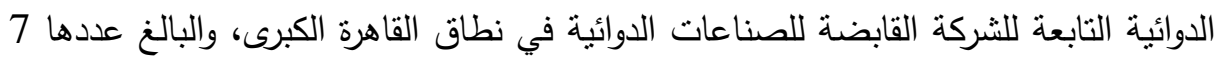
شركات، وعددهم 15537 موظف وهذا الاستهداف لهذا العدد سيعطي نتائج دقيقة، وفيما يلي لئه

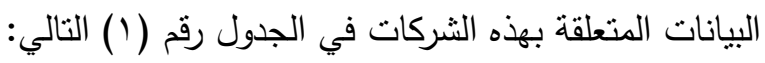
جدول ( ) (1) عدد العاملين حسب الثركات التابعة بمجتمع الدراسة

\begin{tabular}{|c|c|c|c|}
\hline النسبة المئوية & عدد العاملين & الثـــــركة & 5 \\
\hline$\% \backslash 1, Y \wedge$ & IVOT & شركة مصر للمستحضرات الدوائية. & 1 \\
\hline$\% 19, \mathrm{YV}$ & T११६ & شركة تتمية الصناعات الكيماوية "سيد". & T \\
\hline$\% 10,01$ & $\overline{T \leq Y)}$ & شركة النيل للادوية والصناعات الدوائية. & 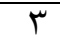 \\
\hline$\% \backslash \vee, .9$ & Y700 & شركة النصر للكيماويات الدوائية & $\varepsilon$ \\
\hline$\% \backslash 1, \varepsilon \varepsilon$ & IVVV & شركة ممفيس للأدوية والصناعاتالكيماوية. & 0 \\
\hline$\% \backslash \uparrow, \wedge \varepsilon$ & YIIV & ثركة القاهرة للذدوية والصناعات الكيماوية. & 7 \\
\hline$\% \wedge, 0$. & . & الثشركة العربية للادوية. & $\mathrm{V}$ \\
\hline$\% 1 \ldots$ & $100 \mathrm{VV}$ & 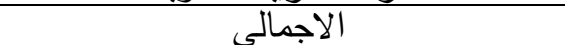 & \\
\hline
\end{tabular}

المصدر: من إعداد الباحثين من واقع بيانات إدارة الموارد البشرية بالثركة القابضة

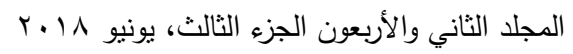


عينة الدراسة: استعان الباحثون بطريقة العينة الطبقية العشوائية في اختيار عينة الدراسة، وقد استخدم الباحثون طريقة النسب والتتاسب، وتم اختيار عينة من مجتمع الدراسة باستخدام

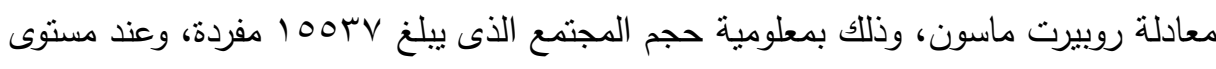

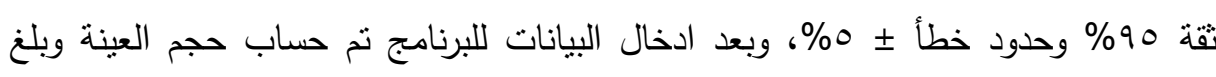

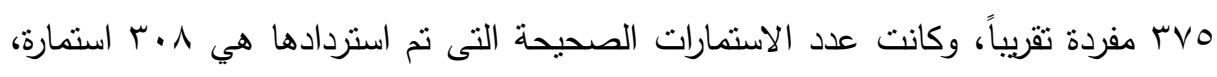

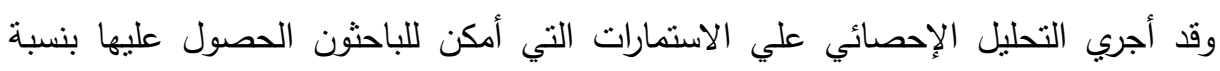

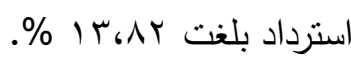
قياس متغيرات الدراسة: في ضوء الدراسات السابقة التي أُطلع عليها الباحثون، فقد إعتمد فئن الباحثون فى قياس المتغير المستقل نظم الإدارة البيئية (متغير مستقل) والاستغراق الوظيفي (متغير تابع) علي الأبعاد التالية: المتغير المستقل: (تطبيق نظم الإدارة البيئية)، وتمثله الأبعاد الخمسة التالية: (السياسة البيئية، التخطيط، التتفيذ والتشغيل، الفحص والإجراءات التصحيحية، المراجعة الإدارية).

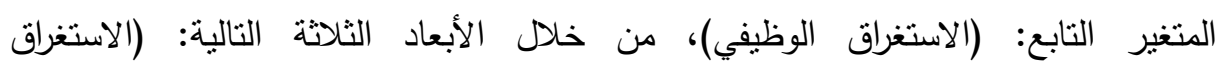
المعرفي/الإدراكي، الاستغراق الثعوري، الاستغراق الجسدي). أداة تجميع بيانات الدراسة الميدانية: قام الباحثون بتصميم قائمة استقصاء لتجميع الإقيع البيانات من مفردات البحث، حيث مر إعدادها وتصميمها بالخطوات التالية: الخطوة الأولى: إعداد قائمة الاستقصاء فى صورتها الأولية: إعتمد الباحثون تصميم قائمة ونهات

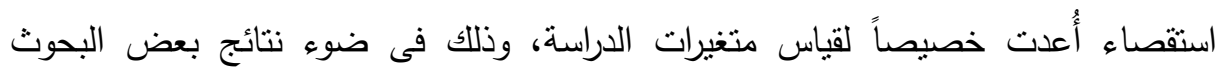
والدراسات والكتابات العلمية السابقة، وكذلك فى ضوء اعلى ما كثنفت عنه نتائج الدراسة الاستطلاعية.

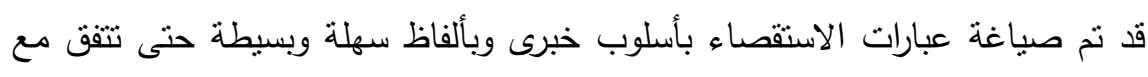

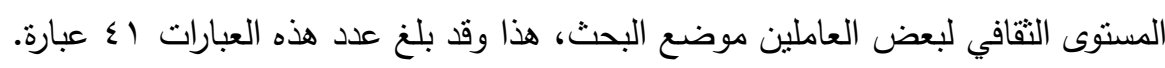

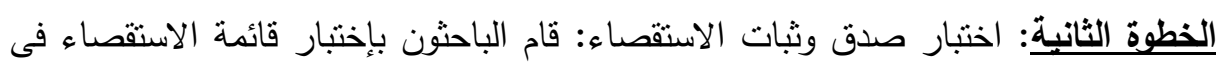
صورتها المبئية من خلال التعرف على صدقها وثناتها وذلك على النحو التالى: 
- أُجرى الباحثون اختبار مبئيى لقائمة الاستقصاء حيث نم عرضها أيضاً فى صورتها

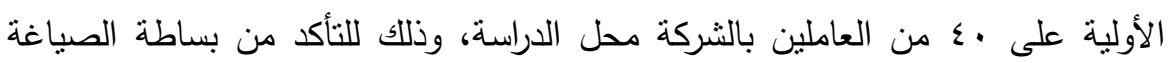

ووضوح اللغة، وللتأكد أيضاً من صلاحية الاستقصاء من الناحية الميدانية.

- نم إجراء اختبار ثبات للتأكد من إمكانية الإعتماد على نتائج البحث فى تعميم النتائج،

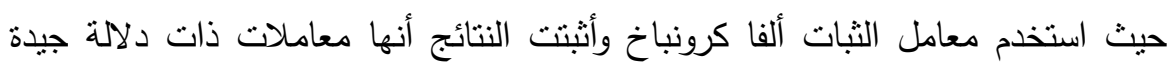

لتحقيق أهداف البحث، ويمكن الاعتماد عليها فى تعميم النتائج على مجتمع الدراسة.

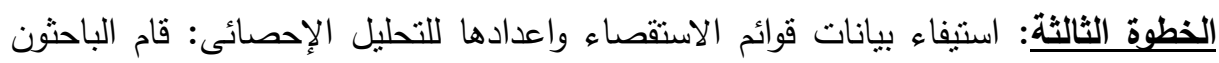

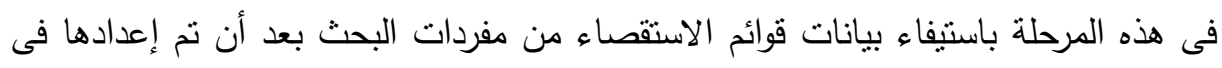

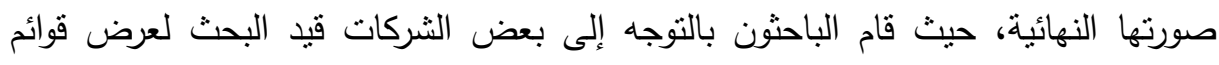
الاستقصاء على بعض العاملين عن طريق المقابلات الثخصية التى أجروها معهم. هذا وقد تم مراجعة قوائم الاستقصاء بعد أن تمت الإجابة عليها، ثم قام الباحثون بإنخال

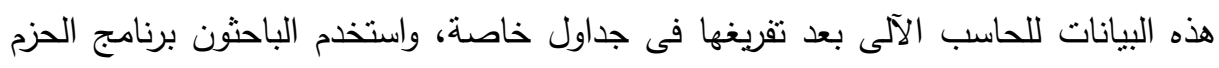
الإحصائية (SPSS v25) فى إجراء التحليل الإحصائى لبيانات الدراسة الميدانية. أساليب التحليل الإحصائي: إعتمد الباحثون على الأساليب التالية:

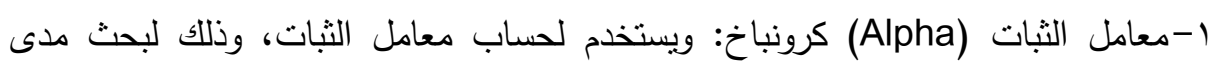
إمكانية الإعتماد على نتائج الدراسة الميدانية فى تعميم النتائج.

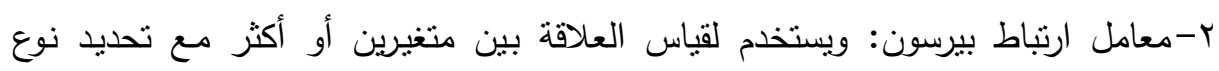
العلاقة وقوتها. ץ-أسلوب الإنحدار البسيط: ويستخدم لحساب معاملات الإنحدار المتغير المستقل مع المتغير التابع. حدود البحث: الحدود الزمنية: تتمنل الحدود الزمنية للاراسة فى الفترة من يولية عام Y V Y الي مارس عام

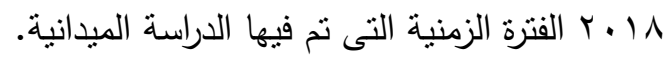


الحدود المكانية: كما تتمثل الحدود المكانية للبحث فى الثركة القابضة للصناعات الدوائية في نطاق القاهرة الكبرى وشركات الصناعات الدوائية التابعة لها- ويرجع اختيار الباحثون لهذه

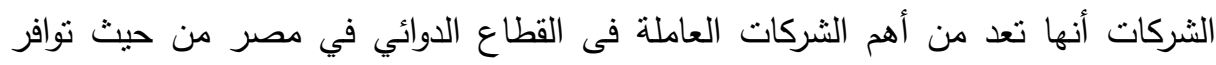
الإمكانات والكوادر الفنية والبشرية اللازمة والتى يمكن من خلالها تصدير المنتجات الدوائية للخارج ووضع نموذج يحتذى به فى كافة الثركات الأخرى فى مصر وكذلك للصلة الوثيقة التي تربط الباحث بهذه الثركات. العدود البشرية: وقد شملت الدراسة الحدود البشرية جميع العاملين بالثركة القابضة للصناعات الدوائية في نطاق القاهرة الكبرى ووفقاً للتنغيرات الديموغرافية الآتية: (النوع المؤهل الوظيفي - المستوى الوظيفي - سنوات الخبرة)، حيث أن لديهم القدرة علي فهم وتحليل محاور الدراسة المختلفة. الحدود العلمية: اقتصرت الدراسة علي دراسة أثز تنبي تطبيق نظم الإدارة البيئية بأبعادها

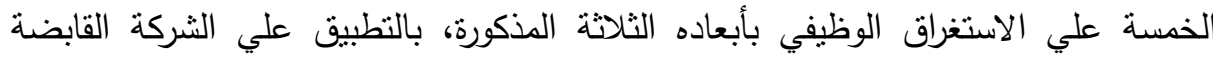
للصناعات الدوائية في نطاق القاهرة الكبرى. صدق وثبات أداة ومقاييس الدراسة: قام الباحثون بإجراء إختبارات الصدق والثبات لقائمة الاستقصاء بغرض بحث مدى إمكانية الإعتماد على نتائج الدراسة الميدانية فى تعميم النتائج وذللك على النحو التالى: تم إجراء اختبار الثبات (Alpha) لمحتويات قائمة الاستقصاء، للتأكد من إمكانية

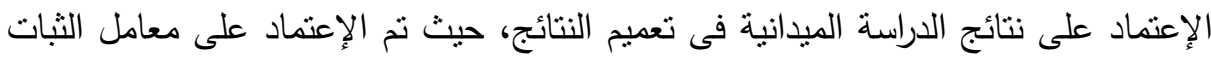

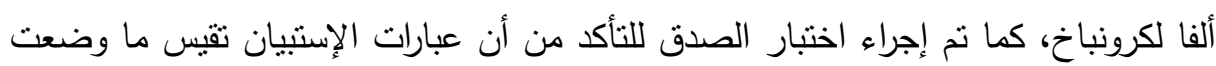

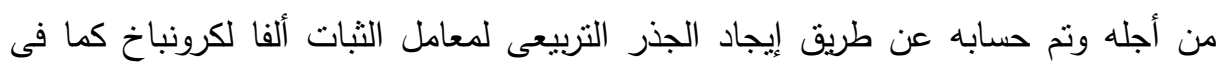

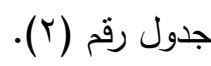


عمرو عواد وآخرون

جدول (r): معاملى الثبات لألفا كرونباخ والصدق الذاتى لأستمارة الاستقصاء

\begin{tabular}{|c|c|c|c|c|}
\hline معامل الصدقى & $\begin{array}{c}\text { معامل الثبات } \\
\text { (Alpha) }\end{array}$ & العبارات & البيـان & 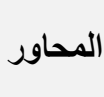 \\
\hline$\cdot, 9 \leqslant \wedge$ & $\cdot, \wedge 9 \wedge$ & r. & نظم الإدارة البيئية & الأول \\
\hline$\cdot, 941$ & - 1, К74 & 7 & السياسة البيئية & 1 \\
\hline$\cdot, \wedge 4 \wedge$ & •, Vor & $\varepsilon$ & التخطبط & r \\
\hline$\cdot, 9 \leqslant \leqslant$ & $\cdot, \wedge 94$ & 7 & التتفيذ والتتغيل & r \\
\hline$\cdot, \lambda 19$ & $\cdot, 7 \times 1$ & $\varepsilon$ & الفحص والإجراءات التصحيحية & $\varepsilon$ \\
\hline$\cdot, 9 \leq$ & $\cdot, \wedge \wedge \varepsilon$ & $r$ & المراجعة الإدارية & 0 \\
\hline$\cdot, 9 \vee \mu$ & $\cdot, 9 \leqslant V$ & 11 & الاستغراق الوظيفي & 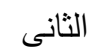 \\
\hline$\cdot, 940$ & $\cdot, \wedge \vee 0$ & 7 & الاستغراق المعرفي/الإدراكي & 1 \\
\hline$\cdot, 941$ & $\cdot$, ATV & 7 & الاستغراق الشعوري & $r$ \\
\hline$\cdot, 9 T Y$ & $\cdot, 101$ & 7 & الاستغراق الجسدي & r \\
\hline
\end{tabular}

المصدر: من إعداد الباحثون من واقع مخرجات برنامج SPSS V25

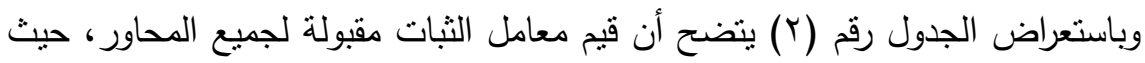
تضمنت استمارة الاستقصاء محورين رئيسيين وكل محور يتكونا من مجموعة من الأبعاد تأخذ

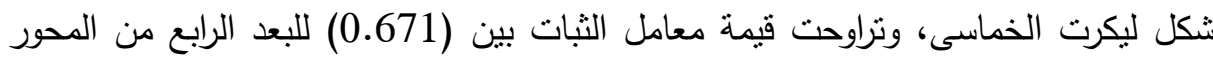
الأول "الفحص والإجراءات التصحيحية" و (0.947) للمحور الثاني "الاستغراق الوظيفي". وباستعراض جدول رقم (r) تراوحت قيمة معامل الصدق بين (0.819) للبعد الرابع من الدحور الأول "الفحص والإجراءات التصحيحية" وبين (0.973) للمحور الثاني "الاستغراق الوظيفي"، حيث أن قيمة معامل الصدق الذاتى هى الجذر التربيعى لقيم معامل الثبات.

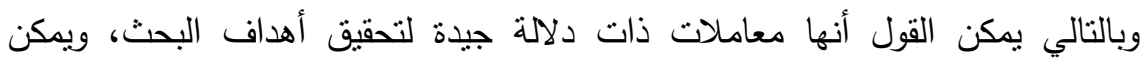

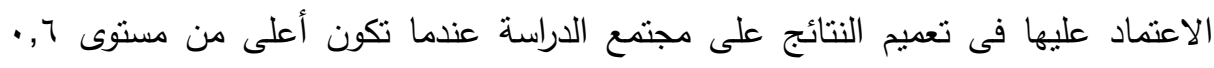
.(Riege, 2003) 
مجلة العلوم البيئية

معهز الدراسات والبحوث البيئية - جامعة عين شمس لهن

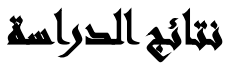

إختبار فروض الدراسة: لاختبار فروض الدراسة تم اختبار وجود علاقة ارتباط معنوية بين أبعاد نظم الإدارة البيئية وأبعاد الاستغراق الوظيفي من وجهة نظر عينة الدراسة. قام الباحثون باستخدام معامل ارتباط بيرسون لتحديد نوع وقوة العلاقة بين أبعاد نظم

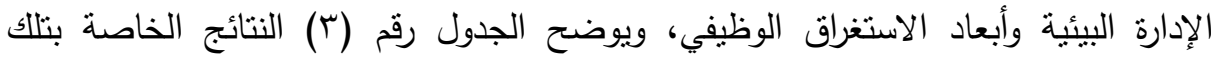

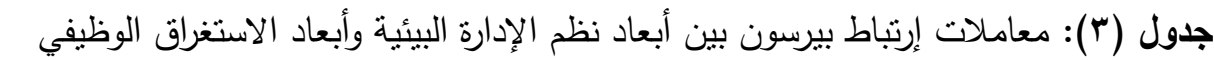

\begin{tabular}{|c|c|c|c|}
\hline الاستغرلق & الثعوري الاستغلق & المعرفي/الإدراكي & \\
\hline ד & VYA. & $q r v$. & السياسة البيئية \\
\hline Tor. & אזד. & 97r. & التخطيط \\
\hline$T V$. & VVO. & $q \pi \varepsilon$. & التنفيذ والتشغيل \\
\hline (T). & Tミ1. & 941. & الفحص والإجراءات التصحيحية \\
\hline 094. & TTV. & 9 १५. & المراجعة الإدارية \\
\hline
\end{tabular}

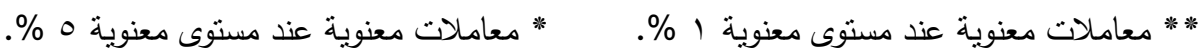
المصدر: من إعداد الباحثين من واقع مخرجات برنامج SPSS V25 المعات

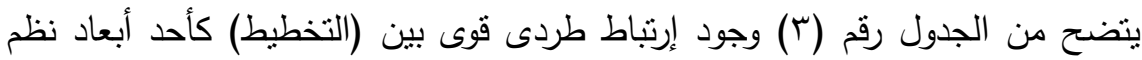

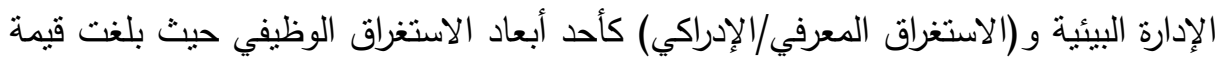
معامل الإرتباط (0.962) ومعنوى عند مستوى معنوية ا\%، وتوجد علاقة طرديه قوية بين (السياسة البيئية) كأحد أبعاد نظم الإدارة البيئية و (الاستغراق المعرفي/الإدراكي) كأحد أبعاد الاستغراق الوظيفي حيث بلغت قيمة معامل الإرتباط (0.937) ومعنوى عند مستوى معنوية

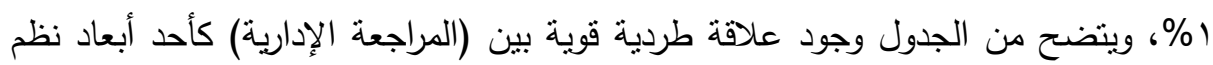
الإدارة البيئية و (الاستغراق المعرفي/الإدراكي) كأحد أبعاد الاستغراق الوظيفي حيث بلثئ بلغت قيمة معامل الإرنباط (928.) ومعنوى عند مستوى معنوية (1\%، وتوجد علاقة طردية قوية بين (الفحص والإجراءات التصحيحية) كأحد أبعاد نظم الإدارة البيئية و(الاستغراق المعرفي) الإدراكي) كأحد أبعاد الاستغراق الوظيفي حيث بلغت قيمة معامل الإرتباط (0.921) ومعنوي 
عند مستوى معنوية ا\%، وكانت أقل قيمة لمعامل الارتباط بين (المراجعة الإدارية) كأحد

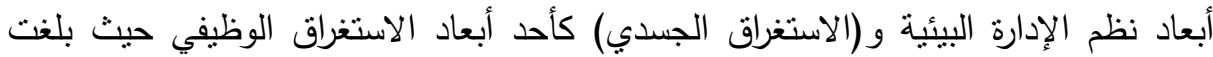
قيمة معامل الإرنباط (0.593) مما يدل على وجود علاقة طردية متوسطة بين المتغيرين ومعنوية عند مستوى معنوية 0\%

مما سبق ينضح وجود علاقة جوهرية بين أبعاد نظم الإدارة البيئية وأبعاد الاستغراق

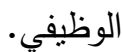

إختبار الفرض الرئيسي الأول: والذى ينص على أنه "لا يوجد تأثنراً جوهرياً للسياسة البيئية

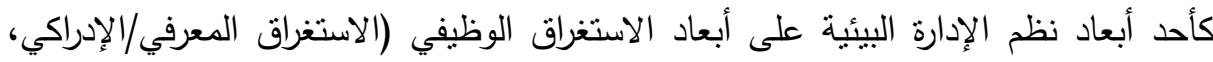
الاستغراق الثعوري، الاستغراق الجسدي) فى الثركة محل الدراسة".

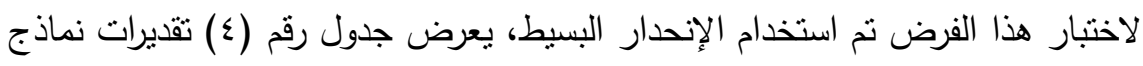

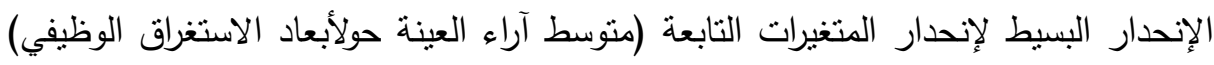

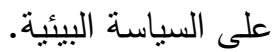
جدول (؛ ): تقديرات نماذج الإنحدار البسيط للسياسة البيئية

\begin{tabular}{|c|c|c|c|c|c|c|}
\hline \multicolumn{4}{|c|}{ التقديرات } & \multirow{2}{*}{$F($ sig. $)$} & \multirow{2}{*}{ التصديدمل $\mathbf{R}^{2}$} & \multirow{2}{*}{ المتغيرات التابعة } \\
\hline Sig. & $\bar{t}$ & $\beta$ & & & & \\
\hline., $1 \times 7$ & $1, \varepsilon 0 \mathrm{~V}$ &., 094 & الثابت & \multirow{2}{*}{ VT, TOV } & \multirow{2}{*}{$\cdot, \wedge \vee q$} & \multirow{2}{*}{ المعرفي/الإدراكي } \\
\hline . & $1,0.7$ & $\cdot, \wedge \wedge \wedge$ & السياسة البيئية & & & \\
\hline$\cdot, Y, Y$ & $1,11\{$ &., 997 & الثابت & \multirow{2}{*}{$\begin{array}{l}11, r \cdot 1 \\
\cdot, \ldots v-\end{array}$} & \multirow{2}{*}{ •, OH } & \multirow{2}{*}{ الاستغراق الثعوري } \\
\hline$\cdot, \ldots V$ & 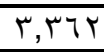 & $\cdot, \mathrm{V} \vee \mathrm{V}$ & السياسة البيئية & & & \\
\hline$\cdot, \cdot 10$ & 1,911 & $1,7 \Lambda$ & الثنابت & \multirow{2}{*}{$\begin{array}{l}7, V \backslash 7 \\
., Y Y V-\end{array}$} & \multirow{2}{*}{$\cdot, \varepsilon \cdot r$} & \multirow{2}{*}{ الاستغراق الجسدي } \\
\hline$\cdot, \cdot T V$ & $r, 091$ & $\cdot, 0 \wedge \varepsilon$ & السياسة البيئية & & & \\
\hline
\end{tabular}

المصدر : من إعداد الباحثين من واقع مخرجات برنامج SPSS V25

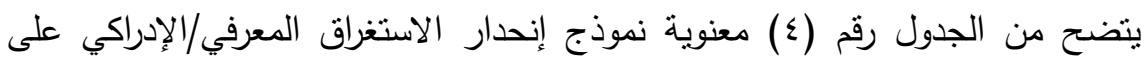
السياسة البيئية من خلا قيمة (sig=0.000)، F(72.357)، كما يتضح معنوية معامل الإنحدار والحد الثابت عند مستوى معنوية 0\% من وبلغت قيمة معامل التحديد (0.879) مما

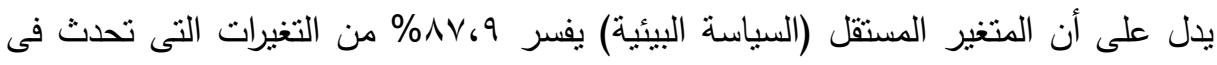

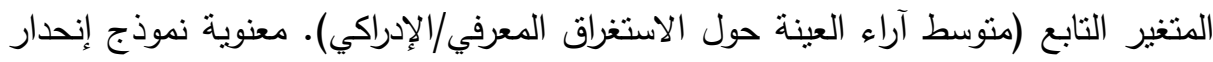

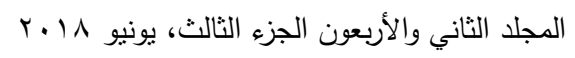




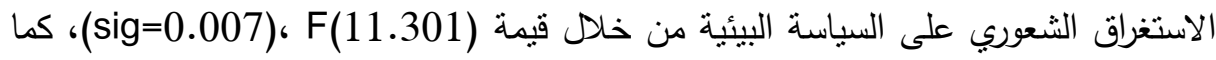

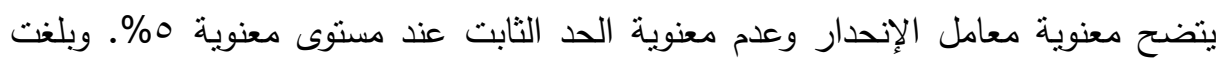
قيمة معامل التحديد (0.531) مما يدل على أن المتغير المستقل (السياسة البيئية) يفسر معربة (الا، \% من التغيرات التى تحدث فى المتغير التابع (الاستغراق الثعوري).

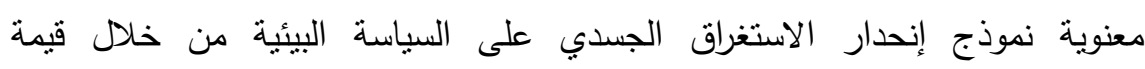

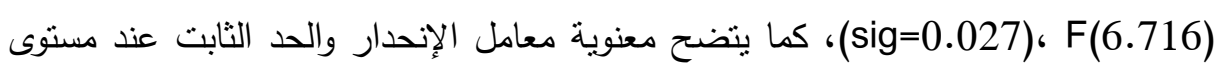

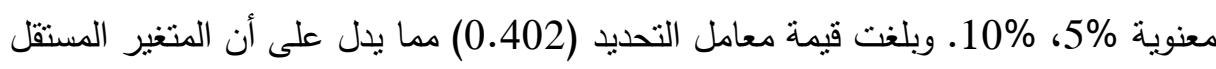
(السياسة البيئية) يفسر \% \% 40.2\% من التغيرات التى تحدث فى المتغير التابع (الاستغراق

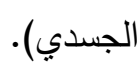
يتضح من الجدول رقم (ع) ان أشارة معاملات الإنحدار موجبة مما يدل على وجود

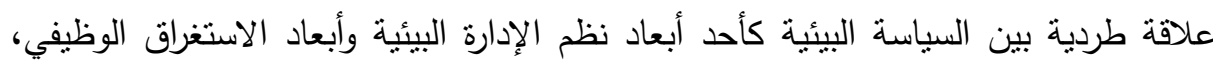

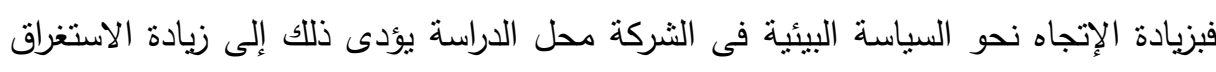
الوظيفي لدي العاملين.

مما سبق يتضح عدم صحة الفرض الرئيسي الأول وصحة الفرض البديل: يوجد تأثيراً

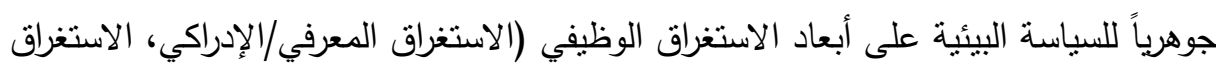
الشعوري، الاستغراق الجسدي) فى الشركة محل الدراسة. اختبار الفرض الرئيسي الثانى: لا يوجد تأثثراً جوهرياً للتخطيط كأحد أبعاد نظم الإدارة البيائية

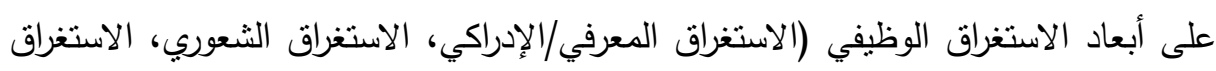
الجسدي) في الشركة محل الدراسة. لاختبار هذا الفرض تم استخدام الإنحدار البسيط يعرض جدول فلدة رقم (0) تقديرات نماذج الإنحدار البسيط لإنحدار المتغيرات التابعة (متوسط آراء العينة حولأبعاد الاستغراق الوظيفي) على التخطيط كأحد أبعاد نظم الإدارة البيئية. 
عمرو عواد وآخرون

جدول (0): تقديرات نماذج الإنحدار البسيط للتخطيط

\begin{tabular}{|c|c|c|c|c|c|c|}
\hline \multicolumn{4}{|c|}{ التقديرات } & \multirow{2}{*}{$F($ sig.) } & \multirow{2}{*}{$\begin{array}{c}\text { التحديدامل } \\
\text { Re }^{2}\end{array}$} & \multirow{2}{*}{ المتغيرات التابعة } \\
\hline Sig. & $t$ & $\beta$ & & & & \\
\hline$\cdot, \cdot V$ & $r_{,} \cdot r_{1}$ & $\cdot, q \cdot v$ & الثابت & \multirow{2}{*}{$\begin{array}{c}|r Y, r Y| \\
.\end{array}$} & \multirow{2}{*}{$\cdot, 9 Y 0$} & \multirow{2}{*}{ المعرفي/الإدراقي } \\
\hline . & $11,1 \cdot v$ & $1, r \leqslant 9$ & التخطبط & & & \\
\hline$\cdot, \wedge 9 \vee$ & תזו, & •, IAY & الثابت & \multirow{2}{*}{$\begin{array}{l}V, A Y \varepsilon \\
\cdot, \cdot 19-\end{array}$} & \multirow{2}{*}{$\cdot, \varepsilon r q$} & \multirow{2}{*}{ الشعتغراق } \\
\hline$\cdot, .19$ & r,VqV & $\cdot, 971$ & التخطبط & & & \\
\hline$\cdot, 0 \wedge Y$ & $\cdot, 0 \mathrm{~V}$ & •, 710 & الثابت & \multirow{2}{*}{$\begin{array}{l}V, r q 1 \\
\cdot, \cdot r r-\end{array}$} & \multirow{2}{*}{$\cdot, \varepsilon r_{0}$} & \multirow{2}{*}{ الاستغراق } \\
\hline.,.,$Y T$ & $r, V \backslash 9$ & $\cdot, \wedge r \varepsilon$ & التخطبط & & & \\
\hline
\end{tabular}

المصدر: من إعداد الباحثين من واقع مخرجات برنامج SPSS V25

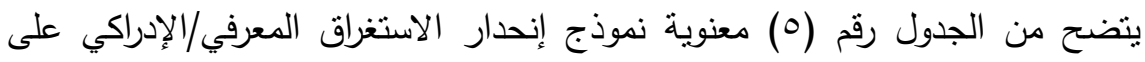
التخطيط من خلال قيمة (sig=0.000)، F(123.371)، كما يتضح معنوية معامل

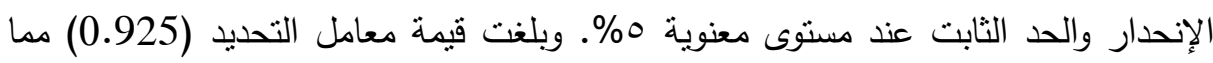

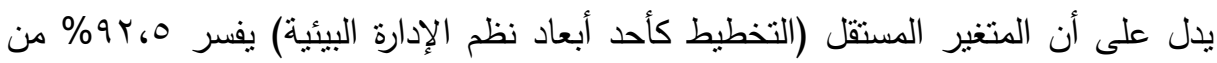

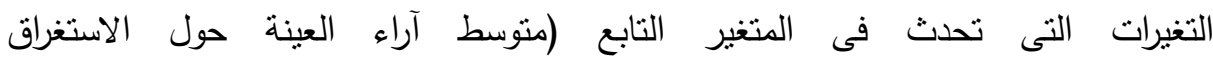
المعرفي/الإدراكي).

معنوية نموذج إنحدار الاستغراق الشعوري على التخطيط كأحد أبعاد نظم الإدارة البيئية

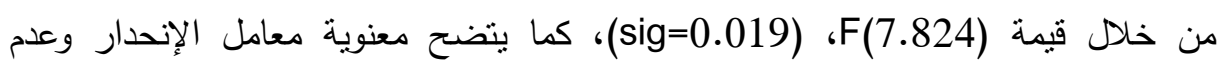
معنوية الحد الثابت عند مستوى معنوية 0\%. وبلغت قيمة معامل التحديد (0.439) مما يدل

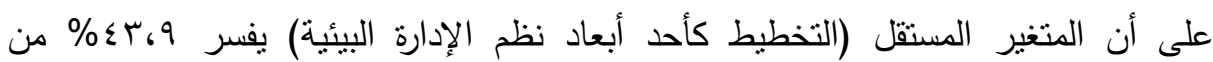
التغيرات التى تحدث فى المتغير التابع (متوسط آراء العينة حول الاستغراق الثعوري). معنوية نموذج إنحدار الاستغراق الجسدي على التخطيط كأحد أبعاد نظم الإدارة البيئية من خلال قيمة (sig=0.022)، F(7.391)، كما يتضح معنوية معامل الإنحدار وعدم الإنغراف معنوية الحد الثابت عند مستوى معنوية 0\%، وبلغت قيمة معامل التحديد (0.425) مما يدل

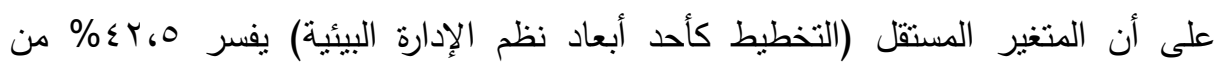
التغيرات التى تحدث فى المتغير التابع (متوسط آراء العينة حول الاستغراق الجسدي). 
يتضح من الجدول رقم (0) أن إثنارة معاملات الإنحدار موجبة مما يدل على وجود

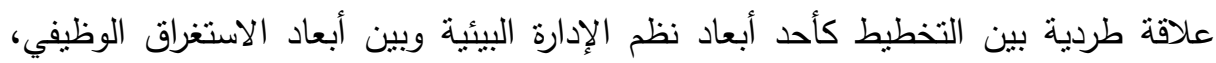

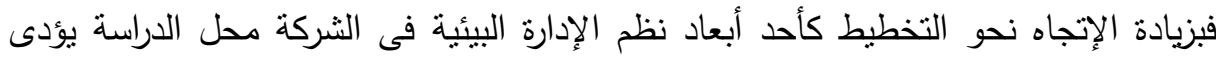
ذلك الى زيادة الاستغراق الوظيفي للعاملين. مما سبق يتضح عدم صحة الفرض الرئيسي الثانى وصحة الفرض البديل: "يوجد تأثيراً

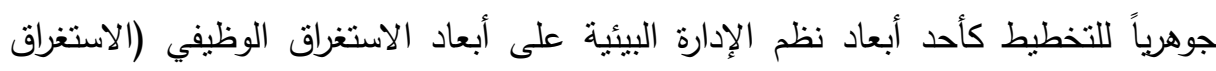
المعرفي/الإدراكي، الاستغراق الثعوري، الاستغراق الجسدي) فى الشركة محل الدراسة". الفرض الرئيسي الثالث: "لا يوجد ثأثثراً جوهرياً للتففيذ والتشغيل كأحد أبعاد نظم الإدارة البيئية على أبعاد الاستغراق الوظيفي (الاستغراق المعرفي/الإدراكي، الاستغراق الثعوري، الاستغراق الجسدي) فى الثركة محل الدراسة".

لاختبار هذا الفرض نم استخدام الإنحدار البسيط يعرض جدول رقم (؟) تقديرات نماذج

الإنحدار البسيط لإنحدار المتغيرات التابعة (متوسط آراء العينة حول أبعاد الاستغراق الوظيفي)

على التنفيذ والتتشيل كأحد أبعاد نظم الإدارة البيئية.

جدول (†): تقديرات نماذج الإنحدار البسيط للتففيذ والتشغيل كأحد أبعاد نظم الإدارة البيئية

\begin{tabular}{|c|c|c|c|c|c|c|}
\hline \multicolumn{4}{|c|}{ التقديرات } & \multirow{2}{*}{ F(sig.) } & \multirow{2}{*}{ التحديد } & \multirow{2}{*}{ المتغيرات التابعة } \\
\hline Sig. & $\bar{t}$ & $\bar{\beta}$ & & & & \\
\hline., 007 &., $7.9-$ & . & الثابت & \multirow{2}{*}{ Th, rYT } & \multirow[b]{2}{*}{$\cdot, \wedge \vee r$} & \multirow[b]{2}{*}{ المعرفي/الإدراكي } \\
\hline - & $\Lambda, Y \uparrow$ & $1, .97$ & والتشغيل & & & \\
\hline$\cdot, 90 \mathrm{~V}$ & $\cdot, .00-$ & $\cdot, .01-$ & الثابت & \multirow{2}{*}{$\begin{array}{l}17,7 \cdot r \\
\cdot, \cdot r-r\end{array}$} & \multirow{2}{*}{$\cdot, 7 \cdot 1$} & \multirow{2}{*}{ الثتستغرراق } \\
\hline$\cdot, \ldots r$ & $r, \wedge \Lambda 1$ & $1, .17$ & والتشغيل & & & \\
\hline$\cdot, \varepsilon Y$ & $\cdot, \wedge \Sigma Y$ & $\cdot, 9.1$ & الثابت & \multirow{2}{*}{$\begin{array}{l}1,109 \\
\cdot, .1 \vee-\end{array}$} & \multirow[b]{2}{*}{$\cdot, \leqslant \leqslant 9$} & \multirow{2}{*}{ الاستغري } \\
\hline$\cdot, \cdot, \mathrm{V}$ & r,107 & •, V70 & والتشغيلي & & & \\
\hline
\end{tabular}

المصدر: من إعداد الباحثين من واقع مخرجات برنامج SPSS V25. 
يتضح من الجدول رقم (7) معنوية نموذج إنحدار الاستغراق المعرفي/الإدراكي على التنفيذ والتتغيل من خلال قيمة (F)68.226، (sig=0.000)، كما بتضح معنوية معامل الإنحدار وعدم معنوية الحد الثابت عند مستوى معنوية ه\%. وبلغت قيمة معامل التحديد (0.872) مما يدلعلى أن المتغير المستقل (التتفيذ والنتغيل كأحد أبعاد نظم الإدارة البيئية) يفسر \% \% \% من التغيرات التى تحدث فى المتغير التابع (متوسط آراء العينة حول الاستغراق المعرفي/الإدراكي).

معنوية نموذج إنحدار الاستغراق الثعوري على التتفيذ والتشغيل كأحد أبعاد نظم الإدارة البيئية من خلال قيمة (16.602)، (sig=0.003)، كما يتضح معنوية معامل الإنحدار

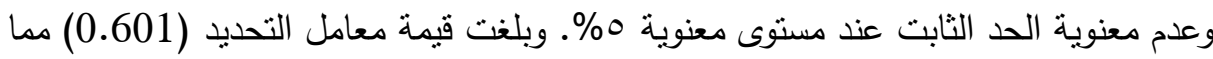

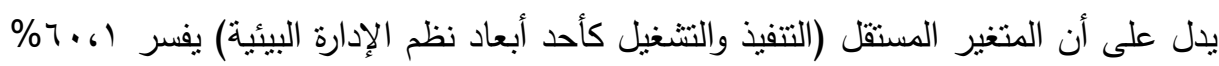

من التغيرات التى تحدث فى المتغير التابع (متوسط آراء العينة حول الاستغراق الثعوري).

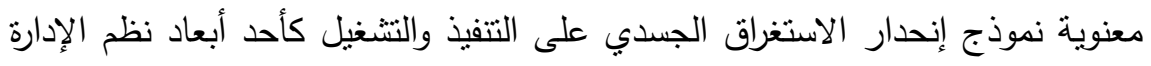

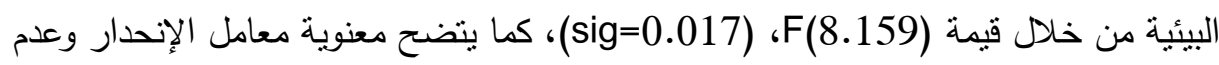
معنوية الحد الثابت عند مستوى معنوية ه\%. وبلغت قيمة معامل التحديد (0.449) مما يدل

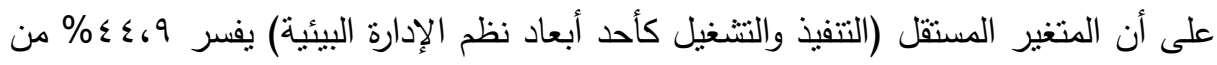
التغيرات التى تحدث فى المتغير التابع (منوسط آراء العينة حول الاستغراق الجسدي). يتضح من الجدول رقم (؟) أن إثارة معاملات الإنحدار موجبة مما يدل على ولى وجود علاقة طردية بين التتفيذ والتتغيل كأحد أبعاد نظم الإدارة البيئية وبين أبعاد الاستغراق

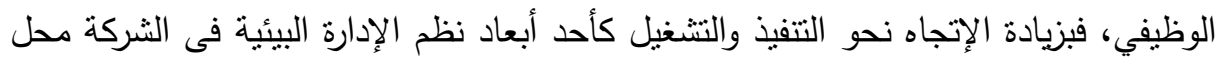
الدراسة يؤدى ذلك إلى زيادة الاستغراق الوظيفي.

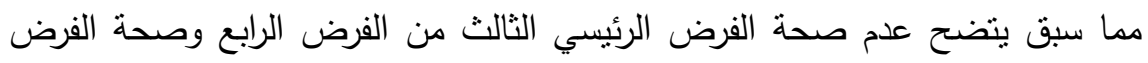
البديل: يوجد نأثيراً جوهرياً للتففيذ والتتغيل كأحد أبعاد نظم الإدارة البيئية على أبعاد الاستغراق الوظيفي (الاستغراق المعرفي/الإدراكي، الاستغراق الثعوري، الاستغراق الجسدي) فى الثركة الثيل محل الدراسة. 
الفرض الرئيسي الرابع: لا يوجد تأثيراً جوهرياً للفحص والإجراءات التصحيحية كأحد أبعاد نظم

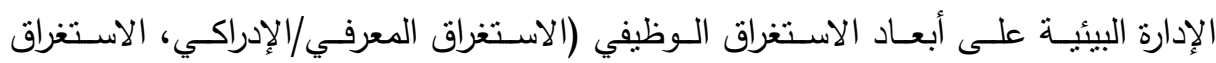
الثعوري، الاستغراق الجسدي) فى الثركة محل الدراسة.

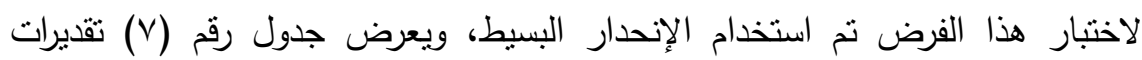
نماذج الإنحدار البسيط لإنحدار المتغيرات التابعة (متوسط آراء العينة حول أبعاد الاستغراق الوظيفي) على الفحص والإجراءات التصحيحية.

جدول (V): تقديرات نماذج الإنحدار البسيط للفحص والإجراءات التصحيحية

\begin{tabular}{|c|c|c|c|c|c|c|}
\hline \multicolumn{4}{|c|}{ التقديرات } & \multirow{2}{*}{ F(sig.) } & \multirow{2}{*}{$\begin{array}{c}\text { معامل } \\
\mathbf{R}^{2} \\
\end{array}$} & \multirow{2}{*}{ التتابعة } \\
\hline Sig. & $\mathbf{t}$ & $\beta$ & & & & \\
\hline$\cdot, \ldots$ & $r \wedge, \varepsilon r$ & $0, \leqslant 0 \leqslant$ & الثابت & \multirow{2}{*}{$\begin{array}{l}07,17 \\
., \ldots\end{array}$} & \multirow[b]{2}{*}{$\cdot, \wedge \Sigma 9$} & \multirow{2}{*}{ الاستغراق } \\
\hline$\cdot, \ldots$ & $\vee, \Sigma १ 々-$ & $\cdot, 091$ & الفحص والإجراءات & & & \\
\hline$\cdot, \ldots$ & $15, .19$ & $0, .17$ & الثابت & \multirow[b]{2}{*}{$\begin{array}{l}7,971 \\
\cdot, \cdot 90-\end{array}$} & \multirow[b]{2}{*}{$\cdot, \leqslant 1$} & \multirow[b]{2}{*}{ الاستغراق } \\
\hline •, rO & r,TrA & -,$\leqslant 70$ & الفصص والإجراءات & & & \\
\hline$\cdot, \ldots$ & $1 T, 1 Y \varepsilon$ & $\varepsilon, \wedge \wedge \wedge$ & الثابت & \multirow{2}{*}{$\begin{array}{l}r, T \cdot r \\
\cdot, \cdot r \Lambda-\end{array}$} & \multirow[b]{2}{*}{ •, r৭1 } & \multirow{2}{*}{ الاستغراق } \\
\hline$\cdot, \cdot Y \Lambda$ & $r, 079$ & • & الفحص والإجراءات & & & \\
\hline
\end{tabular}

المصدر: من إعداد الباحثين من واقع مخرجات برنامج SPSS V25

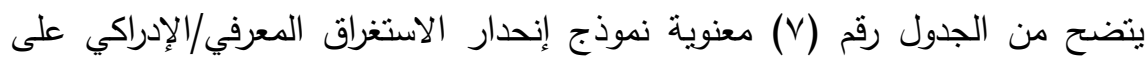

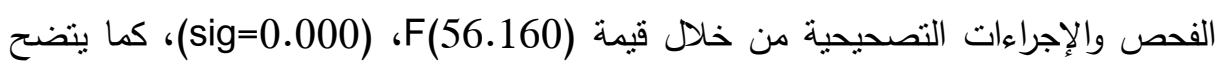

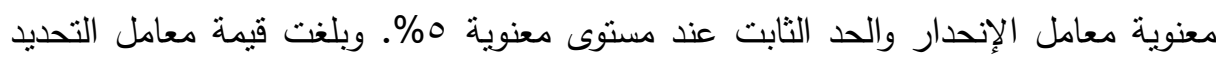
(0.849) مما يدل على أن المتغير المستقل (الفحص والإجراءات التصحيحية) يفسر

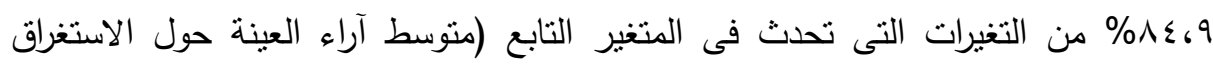

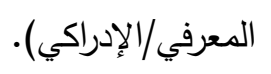


معنوية نموذج إنحدار الاستغراق الثعوري على الفحص والإجراءات التصحيحية من خلال قيمة (6.961)، (sig=0.025)، كما يتضح معنوية معامل الإنحدار والحد الثابت عند مستوى معنوية ه\%. وبلغت قيمة معامل التحديد (0.410) مما يدل على أن المتغير المستقل (الفحص والإجراءات التصحيحية) يفسر اء\% من التغيرات التى تحدث فى المتغير التابع (متوسط آراء العينة حول الاستغراق الشعوري).

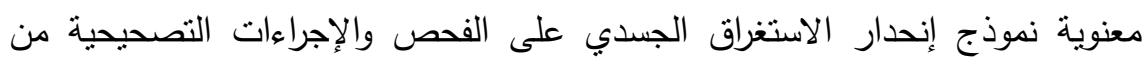
خلال قيمة (F)6.602)، (sig=0.028)، كما يتضح معنوية معامل الإنحدار والحد الثابت

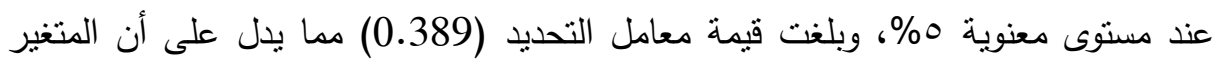

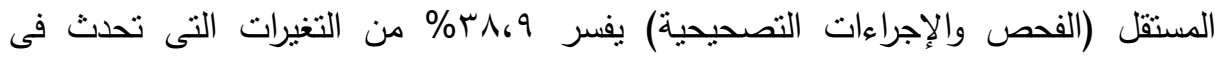
المتغير التابع (منوسط آراء العينة حول الاستغراق الجسدي).

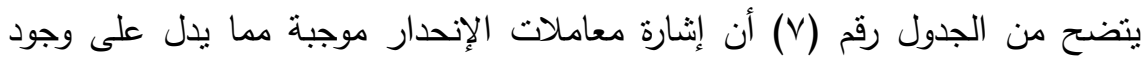
علاقة طردية بين الفحص والإجراءات التصحيحية كأحد أبعاد نظم الإدارة البيئية وبين أبعاد الاستغراق الوظيفي، فبزيادة الإتجاه نحو الفحص والإجراءات التصحيحية كأحد أبعاد نظم الإدارة البيئية فى الثركة محل الدراسة يؤدى ذللك إلى زيادة الاستغراق الوظيفي. مما سبق يتضح عدم صحة الفرض الرئيسي الرابع وصحة الفرض البديل: يوجد تأثيراً

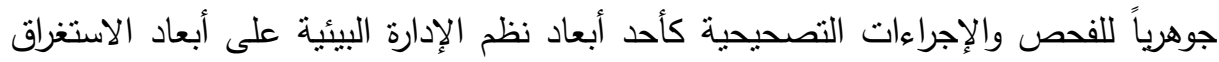

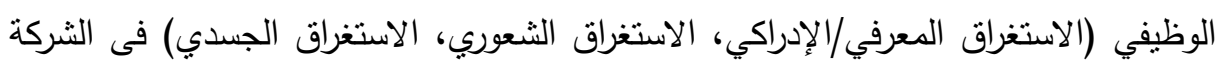
محل الدراسة. الفرض الرئيسي الخامس: لا يوجد نأثثراً جوهرياً للمراجعة الإدارية كأحد أبعاد نظم الإدارة

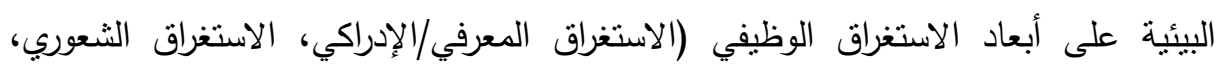
الاستغراق الجسدي) في الشركة محل الدراسة. لاختبار هذا الفرض نم استخدام الإنحدار البسيط يعرض جدول رقدم (^) نقديرات نماذج الإنحدار البسيط لإنحدار المتغيرات التابعة (منوسط آراء العينة حول أبعاد الاستغراق الوظيفي) على المراجعة الإدارية. 
مجلة العلوم البيئية

معهز الدراسات والبحوث البيئية - جامعة عين شمس لهن

جدول (^): تقديرات نماذج الانحدار البسيط للمراجعة الإدارية

\begin{tabular}{|c|c|c|c|c|c|c|}
\hline \multicolumn{4}{|c|}{ التقديرات } & \multirow{2}{*}{$F($ sig.) } & \multirow{2}{*}{$\begin{array}{c}\text { التحديدمل Re } \\
R^{2}\end{array}$} & \multirow{2}{*}{ المتغيرات التابعة } \\
\hline Sig. & $\mathbf{t}$ & $\beta$ & & & & \\
\hline$\overline{+,, \cdots}$ & TV,OTY & $0,7 \mu 1$ & الثابت & \multirow{2}{*}{$\begin{array}{l}T r, 1 Y T \\
\cdot, \ldots\end{array}$} & \multirow[b]{2}{*}{$\cdot, \wedge \backslash 1$} & \multirow{2}{*}{ المعرفي/الإدراكي } \\
\hline$\cdot, \ldots$ & $\vee, \wedge \wedge r$ & $\cdot, 7 \wedge 0$ & المراجعة & & & \\
\hline$\cdot, \cdots$ & $11,01 Y$ & $0, Y \backslash \varepsilon$ & الثابت & \multirow[b]{2}{*}{$\begin{array}{l}\vee, 99 \vee \\
\cdot, \cdot 11-\end{array}$} & \multirow[b]{2}{*}{$\cdot, \varepsilon \leqslant \varepsilon$} & \multirow[b]{2}{*}{ الاستغوراق } \\
\hline$\cdot, \cdot 1 \wedge$ & $r, \wedge r \wedge$ & $\cdot, 00$ & المراجعة & & & \\
\hline$\cdot, \ldots$ & $11, \leqslant 79$ & $\varepsilon, 940$ & الثابت & \multirow[b]{2}{*}{$\begin{array}{l}0, \Sigma \mid Y \\
\cdot, \cdot \leqslant Y-\end{array}$} & \multirow[b]{2}{*}{$\cdot,+01$} & \multirow[b]{2}{*}{ الاستغراق } \\
\hline$\cdot, \cdot, \varepsilon Y$ & T,YYT & $\cdot, \leqslant Y \tau$ & المراجعة & & & \\
\hline
\end{tabular}

المصدر: من إعداد الباحثين من واقع مخرجات برنامج SPSS V25. يتضح من الجدول رقم (^) معنوية نموذج إنحدار الاستغراق المعرفي/الإدراكي على منى المراجعة الإدارية من خلال قيمة (F(62.126، (sig=0.000)، كما يتضح معنوية معامل الإنحدار والحد الثابت عند مستوى معنوية ه\% من مبلغت قيمة معامل التحديد (0.861) مما

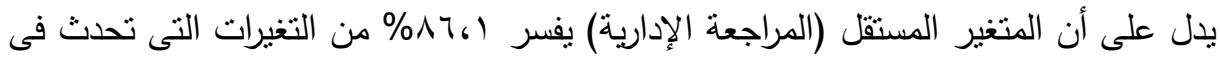
المتغير التابع (متوسط آراء العينة حول الاستغراق المعرفي/الإدراكي). معنوية نموذج إنحدار الاستغراق الثعوري على المراجعة الإدارية من خلال قيمة

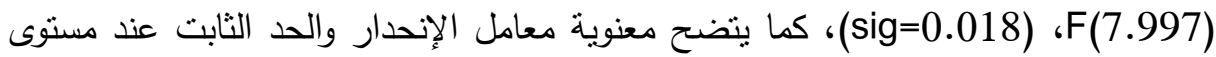
معنوية 0\%. وبلغت قيمة معامل التحديد (0.444) مما يدل على أن المتغير المستقل (المراجعة الإدارية) يفسر ع،ءء٪ من التغيرات التى تحدث فى المتغير التابع (متوسط آراء العينة حول الاستغراق الشعوري). معنوية نموذج إنحدار الاستغراق الجسدي على المراجعة الإدارية من خلال قيمة

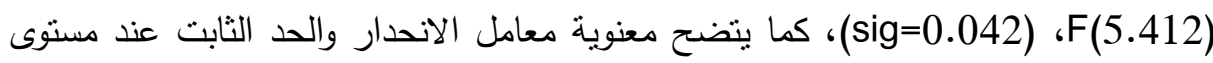
معنوية ٪\%، وبلغت قيمة معامل التحديد (0.351) مما يدل على أن المتغير المستقل

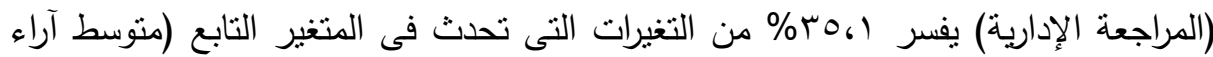
العينة حول الاستغراق الجسدي). 
ويتضح من الجدول رقم (^) أن إثنارة معاملات الإنحدار موجبة مما يدل على وجود علاقة طردية بين المراجعة الإدارية كأحد أبعاد نظم الإدارة البيئية وبين أبعاد الاستغراق الوظيفي، فبزيادة الإتجاه نحو المراجعة الإدارية كأحد أبعاد نظم الإدارة البيئية فى الثركة محل الدراسة يؤدى ذلك إلى زيادة الاستغراق الوظيفي للعاملين. مما سبق يتضح عدم صحة الفرض الرئيسي الخامس وصحة الفرض البديل: يوجد تأثيراً

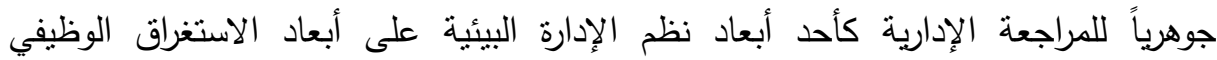

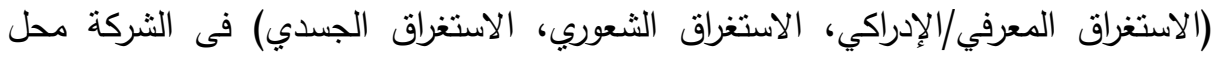

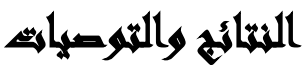

قام الباحثون بتخصيص هذا الجزء لعرض ملخص النتائج وكذلك التوصيات وآليات تتفيذها، وذللك على النحو التالي: النتائج: ا • وجود إرتباط طردى قوى بين (التخطيط)، (السياسة البيئية)، (المراجعة الإدارية) كأحد

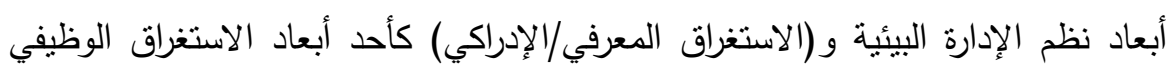

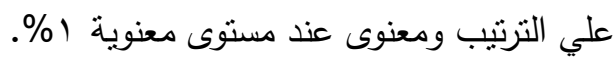
r. يوجد نأثيراً جوهرياً لأبعاد نظم الإدارة البيئية (السياسة البيئية، التخطيط، التنفيذ والتشغيل،

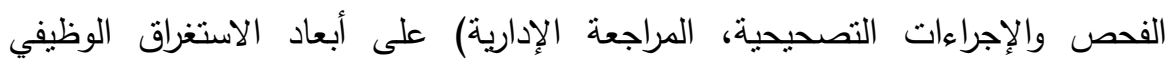

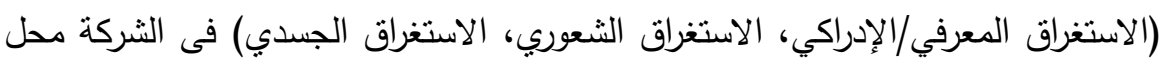

r. تبني الثركة لنظم الإدارة البيئية يرفع من الاستغراق الوظيفي للعاملين بها.

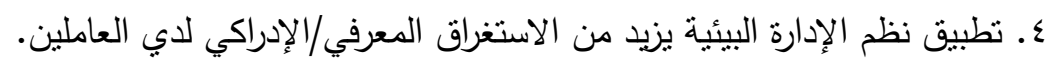

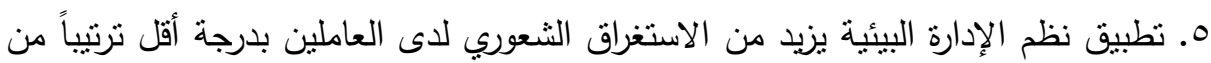

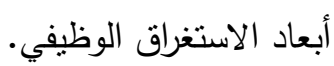


Ү. يزيد الاستغراق الجسدي لدي العاملين نتيجة نطبيق نظم الإدارة البيئية بدرجة هي الأقل ترتيباً علي الإطلاق من باقي أبعاد الاستغراق الوظيفي.

التوصيات وآليات تتفيذها: فى ضوء ما أسفرت عنه نتائج الدراسة يطيب للباحثين أن بأن يختتموا دراستهم بتقديم مجموعة من التوصيات مع اقتراح بعض من الآليات التي يراها الباحثون ملائمة لتفعيل تلك التوصيات ووضعها موضع التنفيذ، ويمكن تلخيص هذه دنه التوصيات في البنود التالية، والجدول رقم (9) النالي يوضح توصيات الدراسة وخطوات التطبيق وجهة التنفيذ والمدى الزمني: جدول (9): يوضح نوصيات الدراسة وخطوات التطبيق وجهة التتفيذ

\begin{tabular}{|c|c|c|c|c|}
\hline الزمني & جهة التفيذ & خطوات التطبيق & التوصية & ? \\
\hline مستمرة & 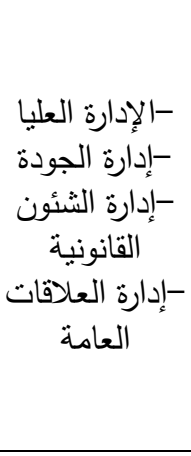 & 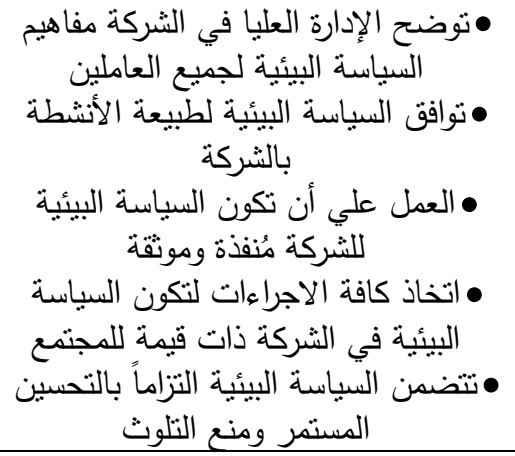 & 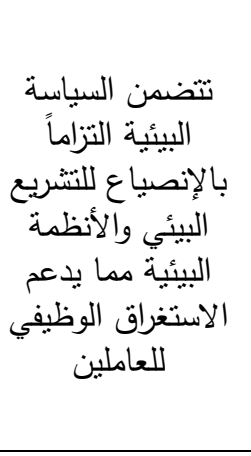 & 1 \\
\hline مستمرة & - & 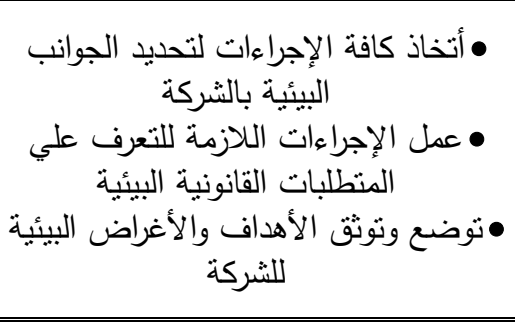 & البالثداد برنامج للإدارة البعال & $r$ \\
\hline
\end{tabular}


تابع جدول (9): يوضح توصيات الدراسة وخطوات النطبيق وجهة التنفيذ

\begin{tabular}{|c|c|c|c|c|}
\hline الزمني & جهة التففيذ & خطوات التطبيق & التوصية & ? \\
\hline بصنمرة & 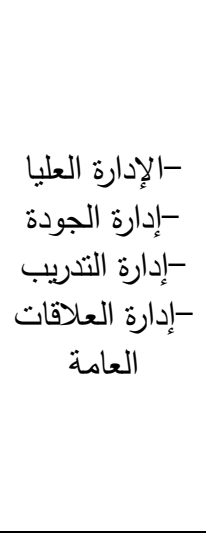 & 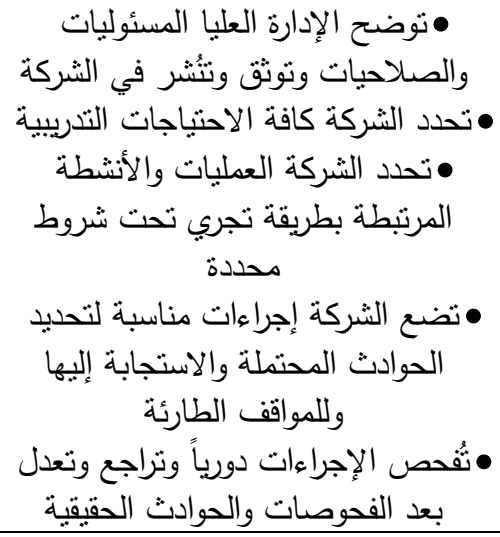 & 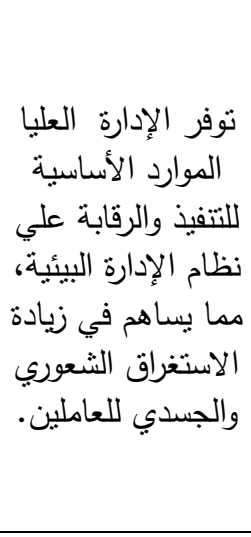 & $r$ \\
\hline بصتمرة & 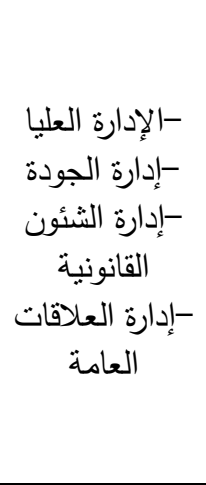 & 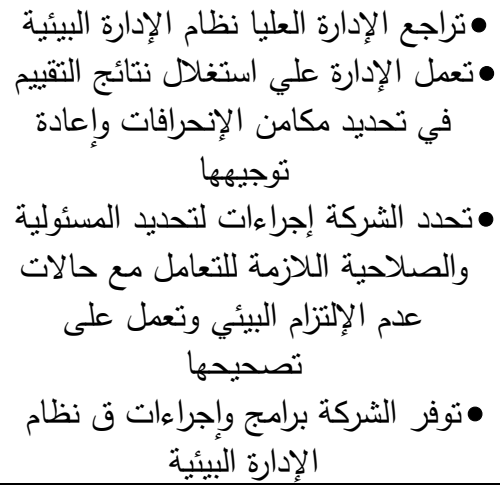 & تعتمد الإدارة العليا & \\
\hline
\end{tabular}

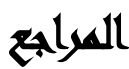

إحسان جلاب(1) ( ب): إدارة السلوك النتظيمي عصر التغيير. دار صفاء للنشر والتوزيع.

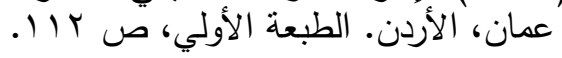

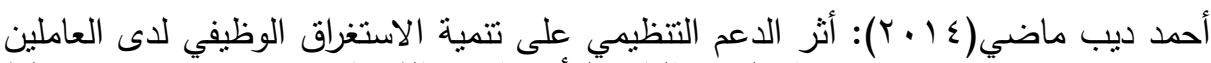

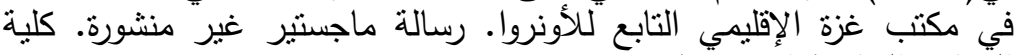

التجارة، الجامعة الإسلامية بغزة. 
مجلة العلوم البيئية

معهز الدراسات والبحوث البيئية - جامعة عين شمس لئه

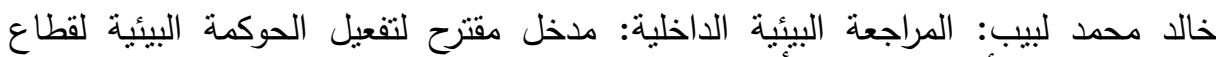

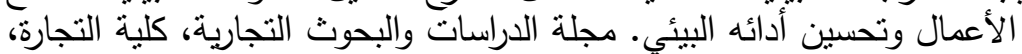

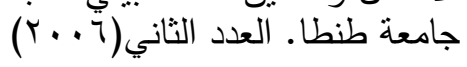

خميس ناصر محمد: تأثثر الثقافه التتظيمية فى تبنى نظام الإداره البيئيه

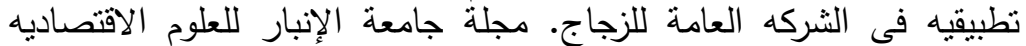

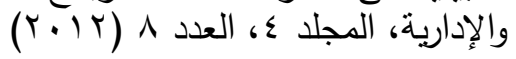

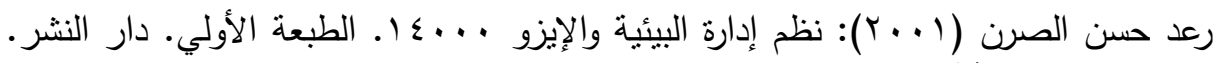

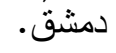

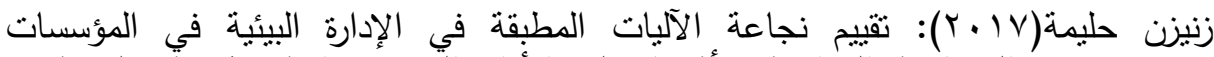

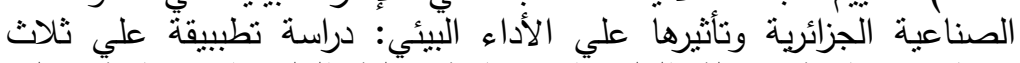

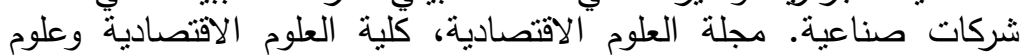
التسيير ، جامعة باجي مختار ، الجزائر .

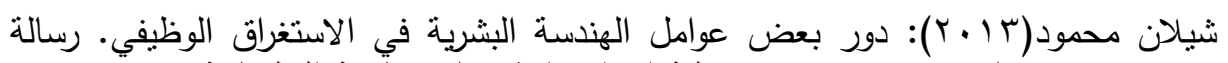
ماجستير غير منشورة. كلية الإدارة والاقتصاد، جأمعة السليمانية الإنية

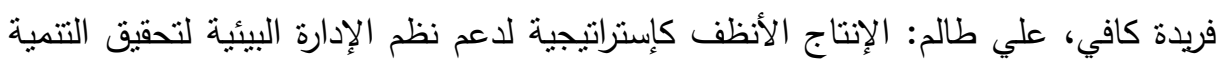

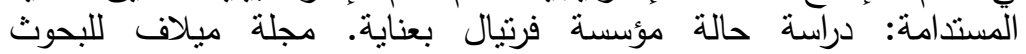

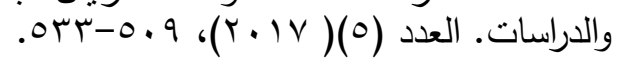

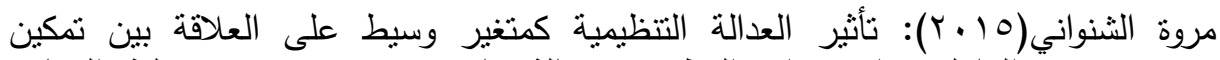

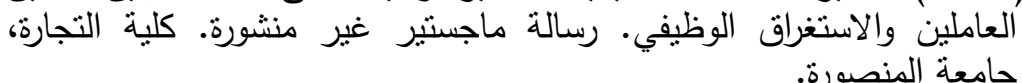

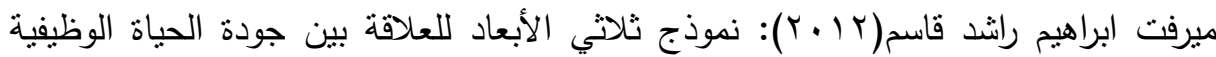

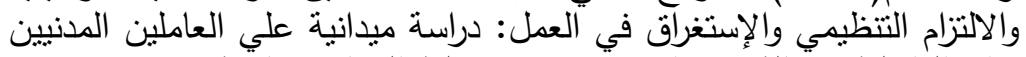

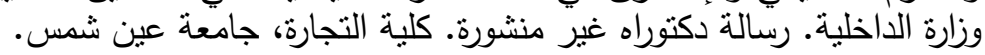

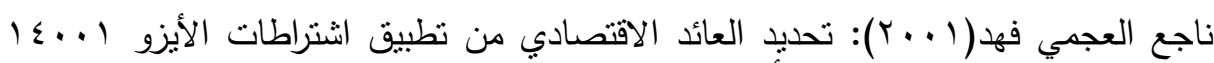

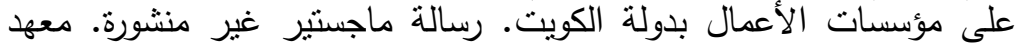
الدراسات والبحوث البيئية، جامعة عين شمس. لألئ رولة

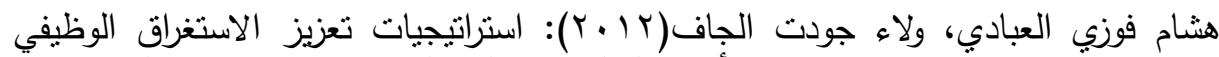

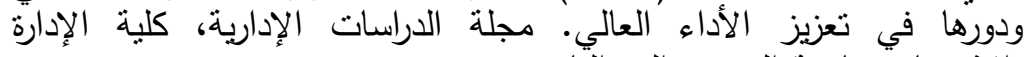

والاقتصاد، جامعة البصرة، العددالتاسع.

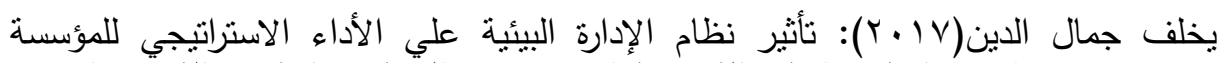

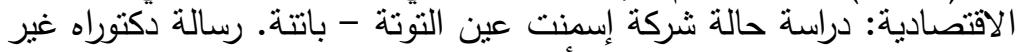

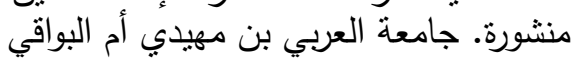

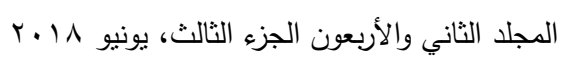


عمرو عواد وآخرون

Bhatia, A.; Deep, G. and Sachdeva, S. (2012): Analyzing the role of job involvement on organisational effectiveness: An empirical study among the employees of Punjab national bank. International Journal of Computing \& Business Research, 2229-6166.

Brattesta, K. I. (2011): An organizational learning perspective on environmental management (Master's thesis).

Ekmekçi, A. K. (2011): A study on involvement and commitment of employees in Turkey. Journal of Public Administration and Policy Research. 3(3), 68.

John Hafer and Martin Thomas (2006): Job Involvement or Affective Commitment A Sensitivity of A Study Of Apathetic Employee Mobility, University of Nebrasks at Omaha, Institute of Behavioral and Applied Management.VOL 2., No.2m P.3.

Joshi, R. J. and Sodhi, J. S. (2011): Drivers of employee engagement in Indian organizations. Indian Journal of Industrial Relations, 162-182.

Kahn, W. A. (1990): Psychological conditions of personal engagement and Disengagement at work.

Lamberts, Eric and Eugene Paoline (2012): Exploring Potential Antecedents of Job Involvement; An Exploratory Study Among Jail Staff, Criminal Justic and Behavior, Vol.12, No. 21.

Reynolds, J. (2004): Helping people learn: strategies for moving from training to learning. Research Report. London: CIPD. p.1.

Tayo, O. and Adedapo, Y. A. (2012): Job Involvement And Organizational Commitment As Determinants Of Job Performance Among Educational Resource Centre Personnel In Oyo State, Nigeria. Welcome To JOSTMED, 153.

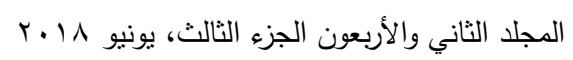




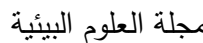

معهد الدراسات والبحوث البيئية - جامعة عين شمس لئن

\title{
THE IMPACT OF ADOPTION OF ENVIRONMENTAL MANAGEMENT SYSTEMS ON JOB ENGAGEMENT AN APPLIED STUDY ON HOLDIPHARMA
}

\author{
Awaad, A. ${ }^{(1)}$; Abdel-Fattah, M. ${ }^{(1)}$ and El-Shahat, Nehal
}

1) ) Faculty of Commerce, Ain Shams University 2) Institute of Environmental Studies and Research, Ain Shams University

\begin{abstract}
The study aims at studying and measuring the impact of Environmental Management Systems on Job Engagement, An Empirical Study of Holdipharma in Cairo, and whether this influence extends to the important role played by Environmental Management Systems and managers in terms of processes capable of increasing the ability of employees to Job Engagement. It also aims to study the application of the studied companies to environmental management systems by surveying the views and opinions of a sample of the employees of this company. The dimensions of the environmental management systems on the dimensions of employment.

In this study, the researchers adopted a combination of the abstract approach and the deductive approach through the method of theoretical study and field study, the researchers adopted a combination of the abstract approach and the deductive approach through the method of theoretical study and field study. The researchers used a survey list prepared for the purpose of collecting data.

The researchers also used the Alpha-Cronbach coefficient to calculate the stability coefficient, while the correlation coefficients and the simple and multiple regression analysis method were used to analyze the field study data using sample of the 375 individuals.

The researchers found several results that showed a statistically significant effect among all dimensions of EMS, which represents the independent variable and all dimensions of the dependent variable, 286

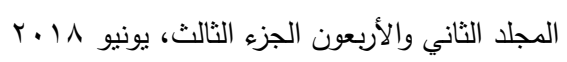


عمرو عواد وآخرون

Functional, as well as researchers of the importance of adopting environmental management systems to support career soundly Holdipharma.

The most important recommendations are Environmental policy includes a commitment to the formulation of environmental legislation and regulations, which supports Job Engagement of staff. Preparation of an effective program of the company for environmental management to achieve environmental goals and objectives helps to boost knowledge / cognitive Engagement, and Senior management provides the basic resources for implementation and control of the EMS, which contributes to increasing the emotional and physical Engagement of staff.

$$
\text { المجلد الثاني والأربعون الجزء الثالث، يونيو \1 بـ }
$$

